University of Louisville

ThinkIR: The University of Louisville's Institutional Repository

Electronic Theses and Dissertations

$5-2012$

\title{
Unearthing Charles Rolwing : the problem of documentation in the small museum.
}

Elizabeth A. H. Rue 1988-

University of Louisville

Follow this and additional works at: https://ir.library.louisville.edu/etd

\section{Recommended Citation}

Rue, Elizabeth A. H. 1988-, "Unearthing Charles Rolwing : the problem of documentation in the small museum." (2012). Electronic Theses and Dissertations. Paper 1240.

https://doi.org/10.18297/etd/1240

This Master's Thesis is brought to you for free and open access by ThinkIR: The University of Louisville's Institutional Repository. It has been accepted for inclusion in Electronic Theses and Dissertations by an authorized administrator of ThinkIR: The University of Louisville's Institutional Repository. This title appears here courtesy of the author, who has retained all other copyrights. For more information, please contact thinkir@louisville.edu. 


\title{
UNEARTHING CHARLES ROLWING: THE PROBLEM OF DOCUMENTATION IN
} THE SMALL MUSEUM

\author{
By
}

Elizabeth A. H. Rue

B.A. Ohio University, 2010

\author{
A Thesis \\ Submitted to the Faculty of the \\ College of Arts and Sciences of the University of Louisville \\ In Partial Fulfillment of the Requirements \\ For the Degree of
}

Master of Arts

Department of Art History

University of Louisville

Louisville, KY

May 2012 
Copyright 2012 by Elizabeth A. H. Rue

All Rights Reserved 


\section{UNEARTHING CHARLES ROLWING: THE PROBLEM OF DOCUMENTATION IN}

THE SMALL MUSEUM

\section{By}

Elizabeth A. H. Rue

B.A. Ohio University, 2010

\section{A Thesis Approved On}

April 23, 2012

By the following Thesis Committee:

John Begley

Peter Morrin

\section{Andy Patterson}




\section{ACKNOWLEDGEMENTS}

I would like to thank my professors John Begley and Peter Morrin for all the help they have given me these past two years, especially all the assistance on my thesis. I would also like to express my thanks to all my wonderful families; the Rues, the Spaldings, the Perrys, the Richards, and the Lambs, who have supported me my entire life and help me grow into the woman I am today. Without all of you, I would not be here writing my thesis and exceeding several expectations of myself. Lastly, I would like to thank the Rolwing family for sharing memories of Charles with me and to help preserve his history for the future. 


\begin{abstract}
UNEARTHING CHARLES ROLWING: THE PROBLEM OF DOCUMENTATION IN THE SMALL MUSEUM

Elizabeth A. H. Rue

April 23, 2012
\end{abstract}

This Curatorial project examines issues that museums face in the documentation of permanent collections, using the Kentucky Museum of Art and Craft (KMAC) and its piece Angel, by Charles Rolwing, as specific examples. The project focuses on museum accession policy, with discussion of works from smaller collections, similar to KMAC, and from larger museums. Specifically, objects are accepted into the collection through acquisition or accession, the former referring to all donated objects accepted by the museum and the latter referring to objects accepted into the permanent collection. A proposed collection policy for KMAC is discussed, including the procedure by which objects are accepted into the collection, and the different ways KMAC could determine its policy for the future. The discussion of accession policy leads to my personal involvement in KMAC and the organization of the permanent collection. The catalogue and accession numbering process implemented by many museums is discussed, demonstrating how these standards can be incorporated in the proposed catalogue for KMAC. Lastly, Charles Rolwing's life as an artist is explored, illuminating the importance of thorough research before fully accessioning objects into the permanent collection of the museum. 


\section{TABLE OF CONTENTS}

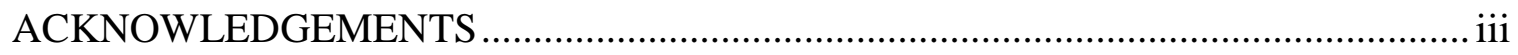

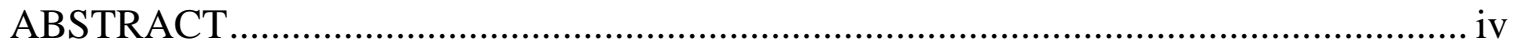

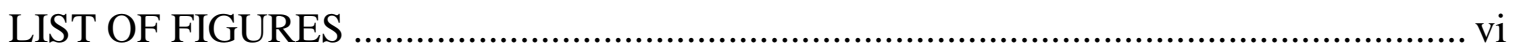

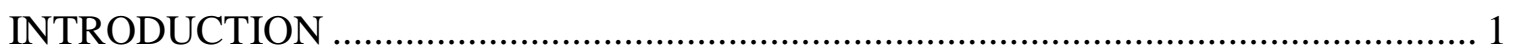

COLLECTION POLICY IN THE MUSEUM ……………......................................... 3

Current KMAC Permanent Collection Practice .............................................................. 4

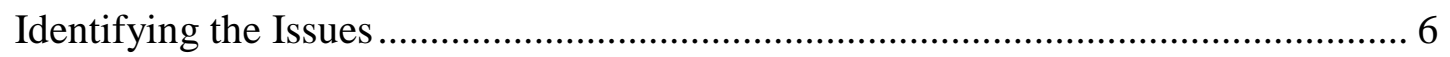

Collection Policy Examples..................................................................................... 7

Developing A New Policy .................................................................................... 21

ORGANIZING THE PERMANENT COLLECTION …………………….................... 27

Manual Catalogue Entry ……………………………….................................. 28

Computer Data Management................................................................................... 34

UNEARTHING CHARLES ROLWING ………………........................................ 37

Interviews and Contacts Made................................................................................ 38

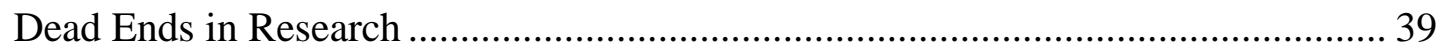

Biography and Art of the Artist ............................................................................. 41

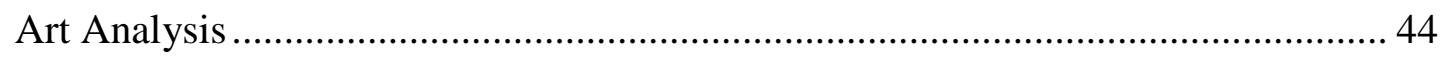

CONCLUSION ............................................................................................. 47

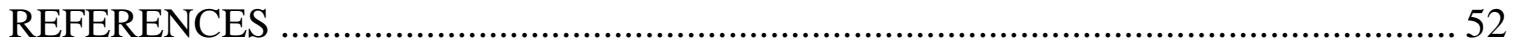

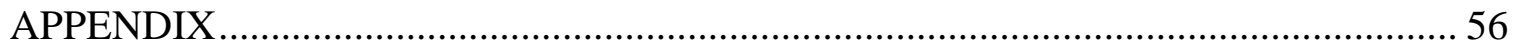

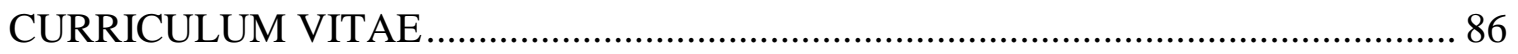




\section{LIST OF FIGURES}

Figure $\quad$ Page

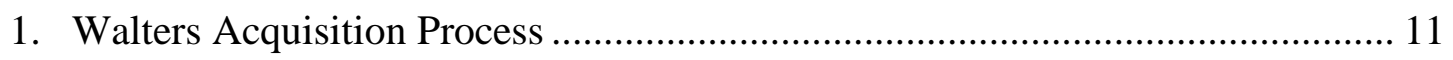

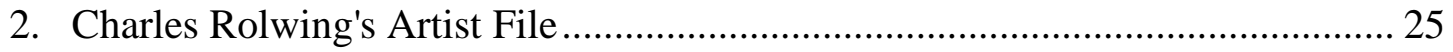

3. Recommended KMAC Acquisition Policy................................................... 57

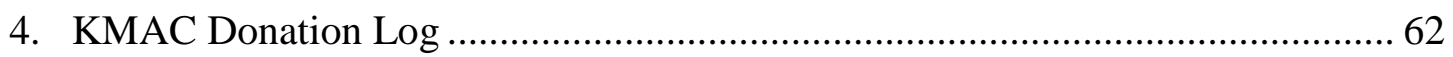

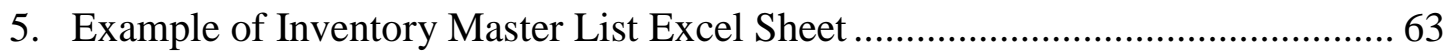

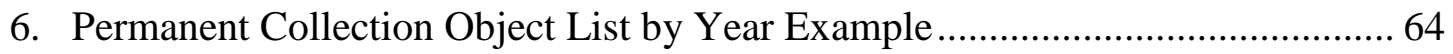

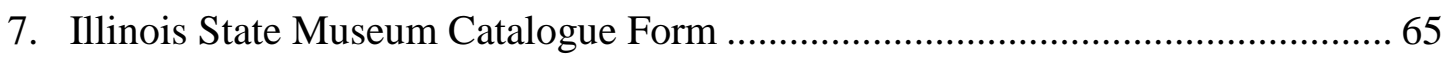

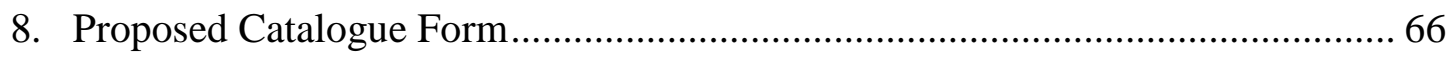

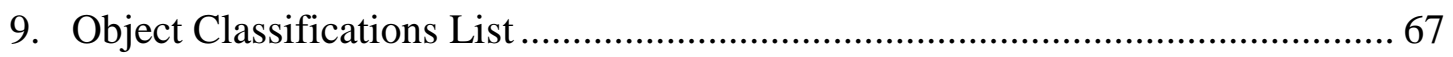

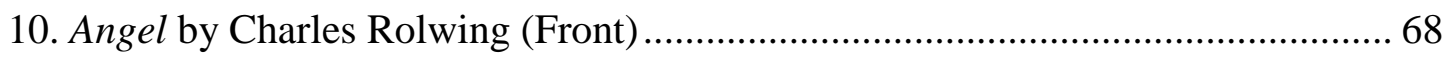

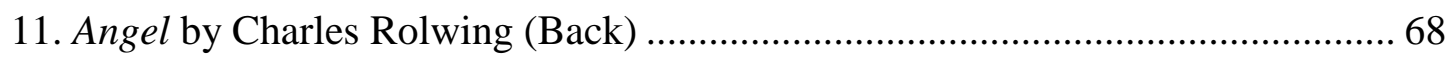

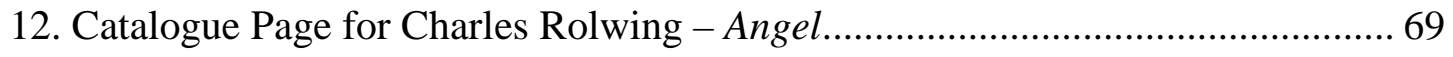

13. From an Angel Sketchbook, 1972 by Charles Rolwing. ..................................... 70

14. From an Angel Sketchbook, 1972 by Charles Rolwing ...................................... 71

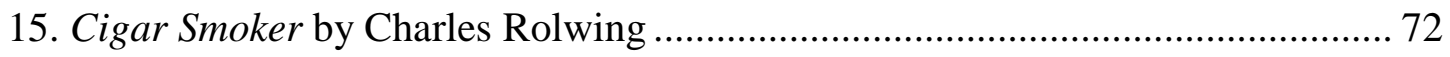

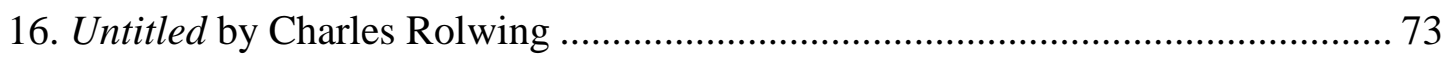

17. Charles Rolwing with Large Wooden Female Sculptures .................................. 74

18. Charles Rolwing and Large Wooden Female Figure.......................................... 75

19. Untitled Four Women by Charles Rolwing ....................................................... 76

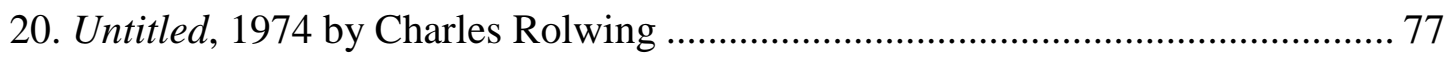

21. Untitled by Charles Rolwing ........................................................................... 78

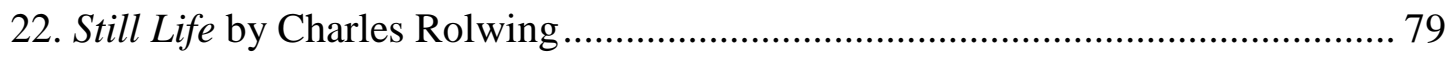

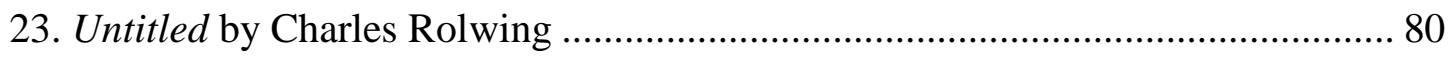

24. Untitled Western Landscape by Charles Rolwing .............................................. 81

25. Untitled Western Six Pack, 1977 by Charles Rolwing ....................................... 82

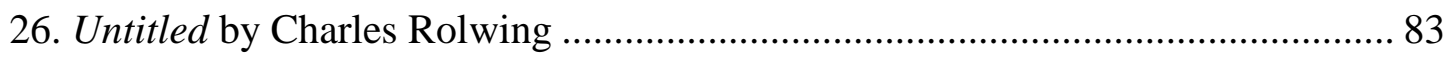

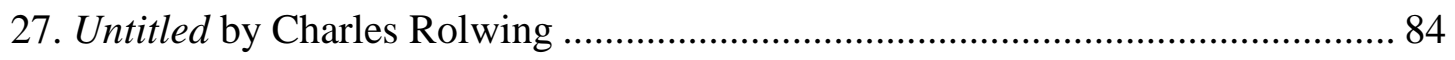

28. Dinner Date, 1963 by Marisol Escobar ............................................................. 85 


\section{INTRODUCTION}

This thesis focuses on a comprehensive permanent collection organizational system completed for the Kentucky Museum of Art and Craft (KMAC) in Louisville, KY. I began working at KMAC on a curatorial project for my M.A. in February 2011, and was asked to return as an Intern to help organize their permanent collection during that summer. Before the internship began, both the Director and the Curator of the museum were asked to resign. After the departure of these two key individuals, it was

discovered that the state of the permanent collection was in significant disarray and required the development of an organizational system.

My project will document KMAC's choice to have a permanent collection, and the way they organized the collection prior to my time there. Changes to the collection registration system are discussed, including an accession numbering system, a new cataloging system, and how the information was gathered to create these two systems. Without question, it is important for every museum to have a system by which all the objects in the permanent collection are organized, and I have presented my recommendations to KMAC for their review and adoption. Along with the organizational aspect of my research, I selected a specific example from the permanent collection, artist Charles Rolwing, to demonstrate why it is critical to keep extensive and accurate records of the objects and the artists accessioned into the permanent collection of the museum. 
Developing the catalogue entry for Charles Rolwing was a difficult process, because there was no artist files for him at the museum. All that was recorded was the name of the artist, title of the piece, the donor of the work, and when it was donated. As a result of this scant information, it was difficult to develop a catalogue entry. When small museums lack the organization system of artist files, donor cards, accession files, or location files (to name a few types a museum can have), it can be difficult to have any sense of organization for collection, detailed information on artists, or on the donors who bring objects to the museum. The Curator should develop this information before the objects are fully accessioned into the collection. In the case of KMAC, a catalogue was finally being created for the permanent collection and it was necessary to complete this research. The optimum process of research and development of information on the collection in museums is examined in greater detail in the collections management chapter.

Defining the process in which objects should be accessioned into the small museum helps determine the best practices that museums such as KMAC should adopt for the future. It can be difficult for small museums because they generally have smaller staffs, or a staff that is mostly made up of volunteers. Setting up a new system for KMAC to implement should help staff, interns, and volunteers in the future who want to help with the permanent collection and the documentation of the objects. 


\section{COLLECTION POLICY IN THE MUSEUM}

An extremely important aspect of a museum's permanent collection management system is creating a comprehensive collection policy because it dictates how the museum will gather new objects and materials for the museum. The policy should be carefully developed prior to beginning to form a collection, and reviewed on a regular basis, especially if the mission of the museum changes. This document helps define and outline different procedures for acquiring and deaccessioning, how to record and care for objects, and other vital procedures to be carried out by the museum in regard to the objects it maintains. The policy is developed by the professional staff of the museum and adopted by the museum's Board. The initial concern of any collection policy is the process of acquiring objects. When museums acquire objects, there should be several important steps before an object is allowed to be included in the collection. The first step is determining the scope and type of collections, so that an institutions' collection supports its mission. Often an outline of acquisition strategy accompanies this statement of collection type to provide a vision for how the collection will be utilized by the institution. The next considerations are that there is adequate space available that is safe, secured, and properly climate-controlled, for the storage of the permanent collection. While each museum will have its own specific process of how it accepts objects to be a part of the collection, there are several important points that should be considered before any acquisition takes place. These include mission, focus, media, and time frame. 
While KMAC has not formally approved a Collection’s Policy I am basing my arguments on a policy they drafted in 2009, although apparently never formally accepted. My first steps in evaluating KMAC's process were to compare its acquisition policies and procedures to both large, internationally renowned, as well as small regional museums.

\section{Current KMAC Permanent Collection Practice}

A document outlining a preliminary collections policy for KMAC was drafted in 2009 however, through my research I found that the issue languished within the Collections Committee and was therefore never formally presented to the Board of Directors for adoption. ${ }^{1}$ This museum started as a gallery with a shop selling exclusively Kentucky artists' works, and later evolved to include a permanent collection as well. The collection now contains approximately 350 objects, the significant majority of them by Kentucky artists. There are also a number of complimentary pieces from surrounding states such as Tennessee, Georgia, and North Carolina. KMAC's objective is to collect fine and craft art, folk art, and decorative arts from Kentucky artists and craft persons. ${ }^{2}$ Examples of these objects can include: furniture, furnishings, decorative or functional pieces, and even toys. ${ }^{3}$ When acquiring work for the collection, the drafted policy states:

The Kentucky Museum of Art \& Craft shall acquire fine art and art craft(s), and object(s) by gift bequest, exchange, and purchase. It shall also accept donations of reference materials, objects to be used for education purposes, equipment, supplies, and monetary contributions to support and further its objectives.

\footnotetext{
${ }^{1}$ Kentucky Museum of Art and Craft, Minutes of Meeting of the Collections Committee, Meeting of 19 November 2009.

${ }^{2}$ Kentucky Museum of Art and Craft, “Collection's Policy” (Louisville, KY: Kentucky Museum of Art and Craft, 2007), 1.

${ }^{3}$ KMAC, “Collection's Policy”, 1.
} 


\section{A. Acquisition Criteria for Collections}

Collection materials must meet all of the following tests before being acquired by KMAC by any means.

1. The acquisition must conform to KMAC's collecting policy.

2. The present owner must be willing to declare in writing that he/she has clear title.

3. No acquisition shall be made if it known or suspected by the Board of Directors, any officer, staff member or employee, to have been illegally obtained by the donor.

4. KMAC must be in a position, both physically and monetarily, to properly care for the proposed acquisition.

5. The significance of the fine art and art craft(s), and object(s) must be demonstrated.

6. The fine art and art craft(s), and object(s) should, if possible, be documented as to provenance.

7. Acquisitions must be free from donor-imposed restrictions.

B. Acquisitions Procedure for Collections

All objects shall be reviewed (as listed in the following categories) for the purposed of acceptance or refusal. The Director, and Curator may view the object(s) at the donor's premises at which time a determination of acceptance or refusal shall be made. Objects may be deposited at KMAC for the purpose of such determination at the owner's risk.

The Curator shall make he determination within 14 days. If the object(s) is refused, the donor will be notified immediately by letter, which states the reason for refusal. Donors will be given 30 days in which to retrieve their object(s). Objects(s) not claimed after 30 days are considered abandoned property and may be disposed of by the Director, in accordance with state laws pertaining to the same. ${ }^{4}$

The document goes on to list how specific acquisitions such as gifts, bequests, exchanges, and purchases are to be administered by KMAC. Each of these decisions is the responsibility of the Director and Curator, with the exception of Exchanges, which is executed by the Board. With every accession of an item into the collection, the Curator is responsible for maintaining all the records of the objects. Having only the Director and Curator handling acquisitions is generally unacceptable for professional accredited

\footnotetext{
${ }^{4}$ Kentucky Museum of Art and Craft, “Collection's Policy”, 2.
} 
museum practices. The KMAC document also discusses items acquired but not

accessioned into the collection:

\section{Acquisition of Non-Collection Items}

Non-collection items such as reference materials, objects to be used for education purposes, equipment, supplies, and reproduction items are accepted donations to support and further the KMAC's objectives. Such donations shall be acknowledged by a letter of thanks to the donor. Non-collection items not to be accessioned, are regarded as expendable, and no commitment is made for their permanent use or preservation. They may be disposed of at the discretion of the Director and Collections Curator. ${ }^{5}$

It is important in the collection policy to differentiate between objects that are acquired by the museum and those that are accessioned into the collection. In KMAC's drafted policy, there is a distinct section that discusses pieces that they will accept but not accession into the collection, and how they will either use or dispose of the items.

\section{Identifying the Issues}

Interestingly, the drafted policy as initially formulated has left the permanent collection in a state where, over time, it has become evident that the document would appear to be insufficient for the needs of the museum. The KMAC policy also states a specific mission but, further into the draft, there begins a broader discussion of movements and styles that the museum collects. For example, within the tradition of Folk Art, there are discreet subareas such as Outsider Art, Self-Taught, and Naïve among others. It is critically important for the museum to document specifically what they collect as an institution. The risk being that with turn-over in staff and even the Board, knowledge (specific and general) of the term Folk Art may not entirely be understood in the context of the mission. Further diluting the intent, KMAC lists "Other” as a broad

\footnotetext{
${ }^{5}$ Kentucky Museum of Art and Craft, “Collection's Policy”, 3.
} 
category of items they will collect. This potentially creates a wide margin that allows for inconsistent or irrelevant objects to be added to the collection.

Another issue found is that when an object is accessioned into the collection, KMAC does not suggest how they will gather information about the piece before it is accessioned, nor do they discuss how they will catalogue the objects. Stating that the curator will handle the records regarding all donations, purchases, bequests, and exchanges can be a lot of work for one person. If the staffing is limited at a smaller museum it would be best practice to allow for interns and volunteers to assist the curator with the record keeping. They could help with initial research of the object and artist, as well as catalogue the objects. If the drafted policy discussed how accession numbering or cataloging would be handled at KMAC, it would allow for any staff member or volunteer to assist the curator with cataloging the collection and keeping records on all the objects.

After working on the organization of the collection and looking over the drafted collection policy the museum has at this time, it is important to look at other examples of museums' collection policies. In order to improve a future policy for KMAC it is useful to examine other institutions' policies in order to compare and assimilate best practices found therein.

\section{Collection Policy Examples}

The Solomon R. Guggenheim Museum in New York City, NY started with a large collection of 610 works of art donated or purchased by the Solomon R. 
Guggenheim Foundation between 1937 and 1949. The collection includes work from these following eras of art: Cubism, Dadaism, Surrealism, Constructivism, Expressionism, Abstract Expressionism, Art Informel, Pop Art, Color Field painting, Minimalism, and Conceptualism. The subsequent years of collecting include more contemporary twentieth and twenty-first century art complements the original works in the collection. The mission of the museum is:

the Solomon R. Guggenheim Foundation, founded in 1937, is to promote the understanding and appreciation of art, architecture, and other manifestations of visual culture, primarily of the modern and contemporary periods, and to collect, conserve, and study the art of our time. ${ }^{6}$

Along with its mission, the museum also has goals for the collecting of the permanent collection in its future years:

The Foundation's goals for the permanent collection are to maintain and to continue to acquire significant works of Twentieth Century, Twenty-First Century and contemporary art in accordance with the Museum's mission. ${ }^{7}$

When the museum looks to accept donations to the permanent collection the Curator must collect the following information on the work(s) of art:

current appraisals that may exist, proof of ownership when pertinent, verification of the title, year, dimensions, provenance, exhibition history and conservation documentation. The work of art shall be photographed and the photos entered, along with the foregoing information, into the museum's collections record files as soon as reasonably possible. ${ }^{8}$

Once this information is gathered, the Director and the museum staff will use the selected information to propose the works of art to be accessioned to the Acquisitions Committee of the Board of Trustees. In turn this committee will come to vote on the objects and

${ }^{6}$ Solomon R. Guggenheim Foundation, “Collections Management Policy” (New York: Solomon R. Guggenheim Museum, 2007), 1.

${ }^{7}$ Guggenheim Foundation, “Collections Management Policy”, 2.

${ }^{8}$ Guggenheim Foundation, “Collections Management Policy”, 3. 
present its recommendation to the entire Board of Trustees, who will make the final determination of acceptance on the object, and how the purchase is to be funded. One important thing that the Guggenheim discusses in its policy, and KMAC should emulate in its policy, is clear statement of the goals of collecting. Having goals and even an outline of specific objects that the museum seeks to obtain can help with ensuring the relevance of objects that are accessioned into the collection.

The Walters Art Museum in Baltimore, MD, started by William Thompson Walters opening his personal home collection to the public in 1874. After he passed, his son Henry brought the collection to its current site for the public in 1909, and became a public institution in 1934. Currently, the museum has a collection of over 28,000 objects that represents fifty-five centuries of art. ${ }^{9}$ Before museum personnel consider an object for acquisition, it must accord with the following principles of collecting:

3.2 All items must have free and clear title.

3.3 Gifts of works of art are accepted on an unrestricted basis, unless previously agreed upon in writing. Gifts will not be accepted that are offered subject to conditions that are regarded as unreasonable or unduly onerous.

3.4 The Walters makes a formal distinction between an accession and an acquisition. To be a candidate for accession into the permanent collection, a work of art must be of outstanding artistic quality and/or art historical significance, and must enhance the Museum's collection. ("Accessioning is the formal process used to accept and record an item as a collection object.... The word 'collection' implies permanence; so should the word 'accession.' Accessioning is a thoughtful process by which only appropriate material is added to a collection.")

3.5 The value or potential value of work of art to one or several of the Museum's audiences must be taken into consideration.

3.6 The physical condition and appropriateness for exhibition of a work of art must be taken into consideration.

3.7 The ability of the Museum to properly store and care for a work of art should be taken into consideration.

3.9 Certain works of art deemed inappropriate for accession into the permanent collection may be accepted as gifts for study purposes, as incidental decoration

\footnotetext{
${ }^{9}$ Walters Art Museum, History of the Walters Art Museum, 2012, www.thewalters.org.
} 
for public or office spaces, or as non-accessioned unrestricted gifts that may be sold. These works are not formally accessioned, but the Registrar's Department tracks their status as non-accessioned acquisitions. (An acquisition is property accepted by the Museum with "no requisite intent to retain." Such property might include works acquired for study purposes, works to be sold at some future date, or works to be used as incidental decoration for public and office spaces.) $)^{10}$

When adding objects to the collection it is important to list terms by which the museum abides by before accessioning them into the collection. Each item listed is essential when acquiring objects. It is also important to note the difference between accession and acquisition, and how objects that are not accessioned are handled. Before the Walters Museum acquires an object, the museum staff goes through rigorous research to determine:

- the ownership history of the work of art;

- the countries in which the work of art has been located and when;

- the exhibition history of the work of art, if any;

- the publication history of the work of art, if any;

- whether any claims of ownership of the work of art have been made;

- whether the work of art appears in relevant databases of stolen works; and

- the circumstances under which the work of art is being offered to the Museum; and

- documentation that shows that the work of art was exported from its country of origin before $1970 .^{11}$

Once the research has been completed, the Walters proceed through acquiring works by the following process:

Works brought in on gift, purchase, or bequest consideration shall be recorded as pre-accessions by the Registrar's Department and assigned an incoming Temporary Loan (TL) number. A Custody Receipt shall be sent to the owner acknowledging receipt and indicating insurance responsibility.

All works considered for acquisition, whether by donation or purchase, must be reviewed by, in sequence ${ }^{12}$ :

\footnotetext{
${ }^{10}$ Walters Art Museum, “Accessions/Acquisitions Policy” (Baltimore: Walters Art Museum, 2006), 2-3.

${ }^{11}$ Walters, “Accessions/Acquisitions Policy”, 4.

${ }^{12}$ Walters, “Accessions/Acquisitions Policy”, 7.
} 
Figure 1 Walters Acquisition Process

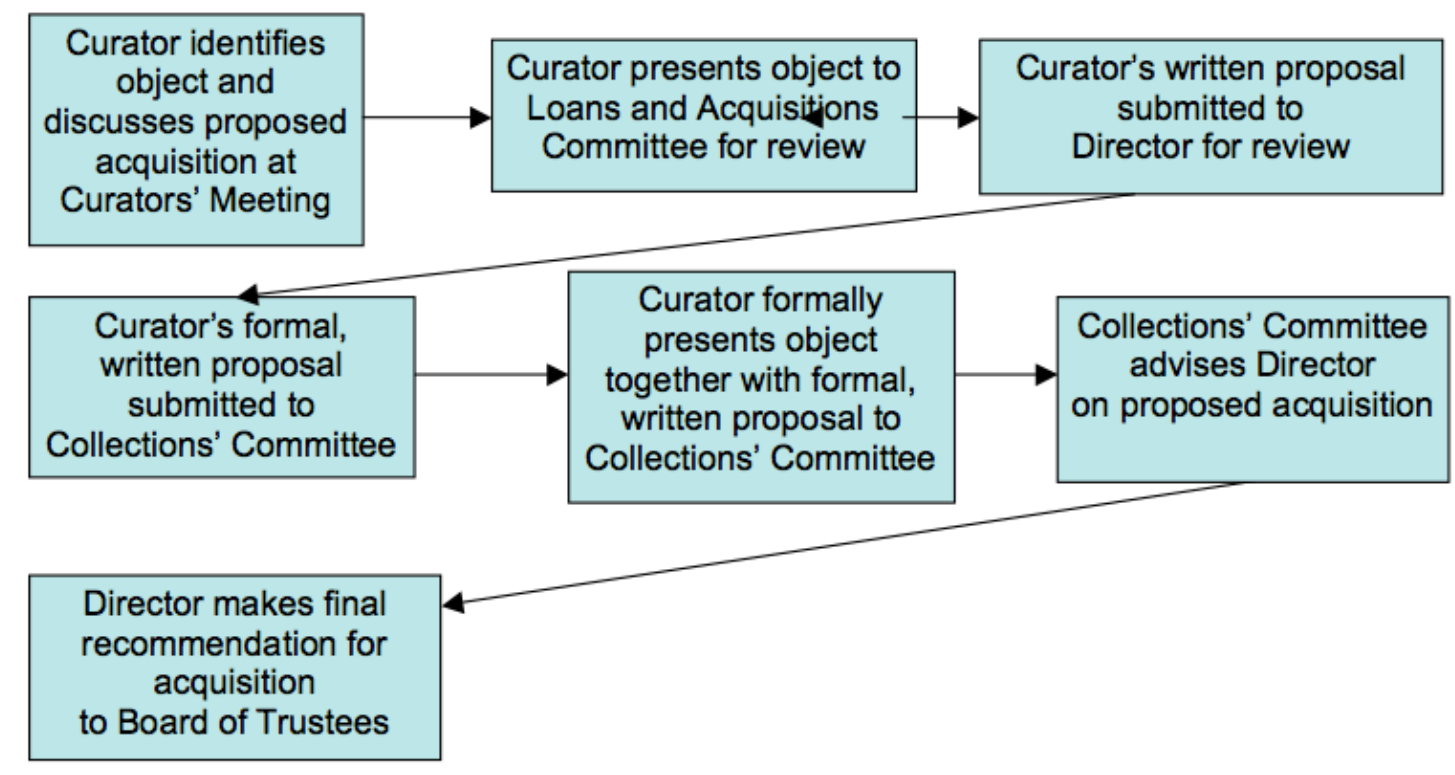

The Walters policy addresses some key points that would be important for KMAC to adopt. One would be to ensure complete research on the object before being acquired into the permanent collection. Second would be defining accessioned and acquired objects for the collection. Having well defined terminology in the policy will help staff and volunteers who work with the collection gain a better understanding. Third would be giving each object a temporary loan number when it arrives at the museum, which confirms that each and every object is recorded. Lastly, the process by which the object is proposed to the Board is important to clarify when acquiring objects at a museum.

The Speed Art Museum in Louisville opened in 1927, and is the oldest and largest museum in Kentucky. Hattie Bishop Speed founded it in memory of her late husband 
James Breckenridge Speed. ${ }^{13}$ Its' collection is focused on Western Art from antiquity to present day, including work from Peter Paul Rubens, Henri Matisse, Pablo Picasso, Frank Stella, Yves Tanguy and many others. ${ }^{14}$ When collecting works of art for the Speed the Curators are:

...charged to collect a broad range of art from various periods, cultures, countries, and categories, including work of living artists...In general, the Museum does not seek objects whose age, rarity, or precious materials alone account for their value. Long-range acquisition plans will be continually reviewed by Curators of their respective areas in consultation with the Director and with the advice and consent of the Committee. ${ }^{15}$

Once the museum finds works to purchase, or individuals or corporations have works to donate, the museum goes through the following process:

1. Before any formal proposal of any acquisition, Curators must confer with the Director concerning selections, priorities, available funds, and considerations of collection support.

2. The Director shall maintain a long-range acquisition program, which will meet the Museum's mission and vision. All potential acquisitions will be presented by the Director to the Committee for its approval or rejection.

3. Ancillary costs incurred due to the acquisition of a work of art, including but not limited to shipping, insurance, travel, auction fees, appraisals, conservation costs, and framing costs may, if necessary, be paid for with acquisition funds. 4. According to the particular type of acquisition, all parties acting on behalf of the Museum in the acquisition of works of art shall comply with the following procedures: ${ }^{16}$

When acquiring works through purchase, the museum lists four different options including: Standard Purchase, Director’s Discretionary Purchases, Purchases at Auction, and Joint Ownership. Each of these involves approval by the Board before proceeding. When objects are donated to the museum they require the following: that all donations are unrestricted, objects must be appraised outside the museum, and financial and other

\footnotetext{
${ }^{13}$ Speed Art Museum, Speed History, 2010, http://www.speedmuseum.org/history.html.

${ }^{14}$ Speed, Speed History, 2010.

${ }^{15}$ Speed Art Museum, “Collection Management Policy” (Louisville, KY: Speed Art Museum, 2008), 2.

${ }^{16}$ Speed, “Collection Management Policy”, 3.
} 
resources to support the object should be considered. The Speed will accept gifts in two ways (1) to be accessioned or (2) not accessioned. The donor will be notified of the gift's status.

All gifts should be recommended to the Committee in one of the following categories [Gifts for Accession, Unaccessioned Gifts, Bequests, and Exchange and Trade] and approved by a majority of the voting quorum. Following acceptance by the Committee of an offered gift of art the Museum will send the donor a deed of gift form. The acquisition of a work into the collection will become official upon the execution of the deed of gift form by the donor and the Museum. Gifts to the collection shall be acknowledged promptly by the Director's Office with information provided by the Registrar's office. ${ }^{17}$

The Speed Art Museum’s policy notes important procedures that all museums should have in their acquisition process. KMAC should adopt the process of confirming whether or not the museum can support special needs contingent upon possession at the time of a donation or purchase, and affirming that there is adequate storage space and financial resources to care for and maintain the objects in the permanent collection.

The International Folk Art Museum in Santa Fe, NM, is one of the museums in the Museum of New Mexico System (MNMS). This museum has a collection of over 130,000 objects from one hundred different countries, shaped by several major donors throughout the history of the museum. ${ }^{18}$ While this is a larger museum, its collection has some similarities to that of KMAC. The International Folk Art Museum outlines what their committees can and will do when it comes time to acquire pieces for the museum:

Museum Collections Committees are the administrative bodies that formulate recommendations concerning changes in status, deaccessions, exchanges, gifts, loans, purchases, conservation, transfers and other related matters. The

\footnotetext{
${ }^{17}$ Speed, "Collection Management Policy”, 4-6.

${ }^{18}$ Museum of New Mexico System, About the Collections, 2012, www.internationalfolkart.org/collections/aboutcollections.html.
} 
committees are structured to draw upon the professional expertise of the museum staff and to create a series of checks and balances between committees and levels of authority. These relationships ensure that actions involving the collections meet the mission statement of the museum and the appropriate criteria for each action. A typical process for passing recommendations affecting collections is as follows: Recommendations are proposed by a Curator, or other person with a demonstrated interest, to the Museum Collections Committee. The Museum Division Director then forwards recommendations to the Board of Regents for final approval. ${ }^{19}$

When acquiring new pieces of art, the MNMS follows these guidelines:

\section{4-A. Accessioning Items into the Collections}

Each Museum of the MNMS may accept gifts or purchase items for the permanent collection if the objects meet all of the following criteria:

1. Support the MNMS mission statement

2. Support research, education, or exhibition uses

3. Have clear and legal title

4. Comply with laws and treaties

5. Do not contradict policies on culturally sensitive materials

6. The status of copyright ownership has been reviewed

7. Do not unnecessarily duplicate other objects in MNMS collections

8. There is adequate storage and/or conservation can be provided

\section{4-D. Final Approval}

Negotiations and correspondence for all proposed gifts and purchases must include a statement to the donor or vendor that the proposal is not finalized until the Board of Regents has given its approval. ${ }^{20}$

Additionally, the MNMS reviews specific gifts while considering the following variables: the condition on which the gift was given, fractional or partial interest gifts, special acquisitions, promised gifts, gifts with potential conflict of interest, and estate gifts. The Museum's policy is detailed with each step they take, ensuring an optimum system of checks and balances in addition to maximum information about the objects they are attempting to acquire for the museum. Having each step of the process outlined is important not only for staff, but also for volunteers who potentially have little idea of the

\footnotetext{
${ }^{19}$ Museum of New Mexico System, “Collections Policy” (Sante Fe, NM: Museum of New Mexico System, 2009), 3.

${ }^{20}$ MNMS, "Collections Policy”, 4-5.
} 
acquisition process. This ensures that both staff and volunteers can carry out the procedures of an acquisition systematically and with consistency. If KMAC were to include this in their future policy, there would be greater potential for interns and volunteers to help with the cataloging and record keeping of the permanent collection. As a museum that relies on volunteers and interns, they should develop the policy to include a procedures manual, so that anyone who comes to help KMAC can have the precise steps to help organize and document the collection.

The Abby Aldrich Rockefeller Folk Art Museum has a collection policy developed by the Colonial Williamsburg Foundation, founded by John D. Rockefeller, which manages several museums and historic buildings in Williamsburg, VA. The museum was formed around a donation of Abby Aldrich Rockefeller's, wife of John D. Rockefeller, personal collection. ${ }^{21}$ The museum's collection:

...encompasses $18^{\text {th }}$-, $19^{\text {th }}$-, $20^{\text {th }}$-, and $21^{\text {st }}$-century American Objects made by minimally or non-academically trained artists and crafts persons, including but not limited to carvings, ceramics, drawings, furniture, metal wares, paintings, sculpture, textiles, decorative useful wares, and whimsical Objects. They are selected on the basis of provenance, condition, historical value, and/or aesthetic quality. The collection also includes $17^{\text {th }}$-, $18^{\text {th }}$-, $19^{\text {th }}$-, and early $20^{\text {th }}$-century American, German, and other toys. These Objects are used for educational exhibitions, interpretations, and research. They also serve as prototypes for reproductions and other retail products. They are not used, except under very restricted circumstances, in office or commercial settings. ${ }^{22}$

The Museum is specific about how it will receive artwork into the collection: the object can be added through gift, bequest, purchase, exchange, or any appropriate transaction where the title is effectively transferred. The museum will not knowingly acquire objects

${ }^{21}$ Abby Aldrich Rockefeller Folk Art Center. American folk portraits: paintings and drawings from the Abby Aldrich Rockefeller Folk Art Center. (Boston: New York Graphic Society, 1981), 11-17.

${ }^{22}$ Williamsburg Foundation, “Collections Management Policy” (Williamsburg, VA, 2010), 2-3. 
that are illegally obtained by the seller or donor; will seek unrestricted donations, and will decline any objects if they hinder the museum. ${ }^{23}$ Then the Museum outlines the exact information required about an object before attempting to acquire it into the collection:

In determining whether such Objects or Artifacts are appropriate for the Collections, written documentation shall be prepared by the relevant specialist Curator. This documentation will include satisfactory evidence of the following:

1. Acquisition of the Object or Artifact is consistent with the collection goals of the Foundation and with this Collections Management Policy;

2. The provenance of the Object or Artifact is satisfactory to the Curatorial staff, supported by a statement of how that conclusion was reached, and by whom;

3. The name and address of the present owner(s), the means of acquisition (purchase, gift, exchange, etc.), the present location and custodian of the Object or Artifact, and the anticipated time of transfer of title and possession to the Foundation;

4. The recommended purchase price of the Object or Artifact, or its approximate value if acquisition is by gift;

5. The appraised value of the Object or Artifact by independent source, if appropriate, and the identity of the source of such appraisal;

6. The transfer of full and absolute title in the Object or Artifact to the Foundation, indicating the manner in which such transfer of title is contemplated (bill of sale, deed of gift, etc.);

7. A description of any restrictions or limitations on the ownership, use, or future disposition of the Object or Artifact by the Foundation;

8. The purpose for which the Object or Artifact is to be used within the foreseeable future, including a statement of its relevance to the Collection;

9. That the care, conservation, and maintenance of the Object or Artifact will not materially increase the financial obligation of the Foundation, or a statement of the extent to which it would;

10. That funding for the purchase of the Object or Artifact, its transportation to Williamsburg, and other related costs, have been arranged and authorized. ${ }^{24}$

When acquiring the work into the collection fully the museum goes through a process where:

An Accessions Committee comprised of the Foundation's Curators, Conservators, and Registrars and chaired by the Vice President for Collections, Conservation, and Museums shall review each Object or Artifact considered for acquisition by purchase, gift, or loan. The Vice President, having given due consideration to the

\footnotetext{
${ }^{23}$ Williamsburg Foundation, "Collections Management Policy”, 6.

${ }^{24}$ Williamsburg Foundation, “Collections Management Policy”, 6-7.
} 
above factors, may accept on behalf of the Foundation such loans and unrestricted gifts as he or she shall deem appropriate.

This extensive process is necessary because knowledge of an items' context and how it will reflect upon and connect to the rest of collection is an important aspect of the museums' body of works. It would be relevant for KMAC to adopt several important aspects of the Rockefeller policy, including a detailed description of future donations and purchases within these parameters, the detailed process of documentation by the Curator before presentation to the Board, and the procedures to be followed from Curator to Board during acquisition of new works of art.

The final museum to discuss is the Kentucky Folk Art Center in Morehead, KY. The museum is affiliated with Morehead State University. As university employees they are entrusted with overseeing all decisions of the featured 1,400 pieces of self-taught art. $^{25}$ The collection includes:

...expressive works of contemporary self-taught art, unschooled art, folk art, "outsider" art, naïve art, isolate art, and/or primitive art. The primary collecting focus will be on works of art in these categories created by artists from Kentucky. "Artists from Kentucky" will be interpreted to mean:

1. Artists born and living in Kentucky;

2. Artists born outside Kentucky who relocated to live in Kentucky, or who were living in Kentucky, at the time of creation of an artwork; or

3. Artists born in Kentucky who relocated to live elsewhere.

The Collection may also include works of art in these categories by artists with no connection to Kentucky. Works of art by non-Kentucky artists will usually only be acquired for the collection as gifts.

The Collection may include any completed, original work of art from the above categories including, but not limited to

1. Paintings, drawings, collages, and other two-dimensional works

2. Sculptures in any medium — wood, stone, papier-mâché, found objects, etc.

3. Canes and walking sticks

${ }^{25}$ Kentucky Folk Art Center, 2012, http://www2.moreheadstate.edu/kfac. 
4. Unfinished works of art by significant Kentucky artists that are considered to be sufficiently important to be worthy of exhibition or of value in research that supports the mission of KFAC.

(Certain unfinished, two-dimensional works-in-progress on paper, created by deceased artists, that are judged as unsuitable for exhibition but which have potential value for research purposes, may be acquired for inclusion in the KFAC Archives.) $)^{26}$

In an institution such as KFAC, it is important to note exactly what they have and what they are seeking in their collection because their focus is on Kentucky folk artists. There can be a broad range within Folk Art and it is necessary to note which types of Folk Art they intend to include in their collection. The museum goes through the following process to acquire art into the permanent collection:

\section{ACQUISITIONS/PURCHASES}

Since the Collection is held in the public trust, ownership of an object carries with it a commitment to its care in perpetuity. The importance of an object considered for acquisition, therefore, must be balanced by thoughtful evaluation of its future storage and conservation needs.

The Director and Curator are responsible for the search for possible acquisitions. No object may be considered for purchase without the Director's consent. All acquisitions are contingent upon verification and unconditional transfer of ownership of the object(s) in question. This procedure is particularly important in the case of purchases, since they represent the expenditure of moneys committed specifically for this purpose. KFAC Collection Policy stipulates that funds allocated for purchases for the Collection shall only be used for the purchase of works by Kentucky Artists. Works by non-Kentucky artists shall only be acquired by means of gifts or bequests.

\section{GIFTS \& BEQUESTS}

While circumstances may dictate some necessary deviations, it is strongly advised that gifts and bequests be of a clear and unrestricted nature and that no work be accepted with a guarantee in perpetuity of an attribution or the circumstances of exhibition. For example, while acceptance of an object as a gift implies that the object will from time to time be placed on exhibit, KFAC will not accept an object as a gift with any guarantee to the donor that the object will be either permanently periodically exhibited.

In keeping with professional standards of ethics, KFAC Collection Policy prevents KFAC staff from providing donors, potential donors, or any other groups

${ }^{26}$ Kentucky Folk Art Center, “Permanent Collection Policy” (Kentucky Folk Art Center, 2009), $1-2$. 
or individuals with an estimate or appraisal, verbal or in written form. While KFAC does not require a formal appraisal or an informal estimate of value, when accepting an object as a gift to the Collection, some form of valuation must be provided by the donor if they wish to have their gift acknowledged by KFAC. Before accepting a gift, KFAC will inform the donor that that legal and ultimate responsibility for furnishing evaluations to governmental tax agencies rests with the donor. In addition, it is unlawful for the Center to initiate or fund appraisals on behalf of donors.

Objects may be added to the collection by way of gifts from outside sources. Requests may be made to potential donors in soliciting such gifts.

Objects may also be added to the collection through bequest. The Director shall negotiate bequests on behalf of the Center, and all negotiations shall be conducted in keeping with the guidelines for accepting gifts outlined here.

Offers of artwork as gifts or bequests to the Permanent Collection will be processed according to established guidelines. After contact by an individual wishing to offer artwork(s) to KFAC, the Curator shall write or otherwise communicate with this individual, informing them of the following KFAC procedures:

1. Photographs of items being offered, together with as much information as possible (name of artist, title, date of work, size, etc.) should be sent to KFAC for consideration by staff and the Permanent Collections Committee.

2. Upon receipt of the above information, the Curator will consult with the Director as to the relevance of the objects to the KFAC Collection.

3. If the objects are not considered relevant to the Collection, the Curator will write this decision to the potential donor in a timely fashion, returning the information to the owner.

4. If the objects are considered relevant, the Curator will consult with the Director and a decision will be made regarding acceptance. If the offer of the gift is conditional upon swift acceptance (such as a gift being given for donor tax deduction purposes near the end of the calendar year) KFAC will expedite the decision as quickly as possible.

5. Once a decision has been reached not to accept an item or items offered, the Director will communicate this decision to the donor.

6. Upon agreement to accept, the Curator will make arrangements for the transfer of the objects to KFAC.

7. Once the work(s) to be donated and the appraisal(s) of value of the gifts are received by KFAC, the Director, or Curator will send a letter of gratitude from KFAC, and will return any other documentation (such as IRS tax exemption forms) requested by the donor. In the event that the donor does not wish to commission an appraisal or provide and estimate of value, the Curator shall assign a current "fair market value" to the object(s) for purposes of insuring the newly acquired works until such time as a formal appraisal of the Collection is commissioned. This internal estimate will be used for insurance purposes only and will not be provided to the donor for use in documenting the gift for the tax purposes.

PURCHASES 
The Curator may recommend to the Director the purchase of an object or objects for the Collection. Upon agreement that the objects are appropriate for the Collection, KFAC will initiate payment, or arrange terms for payment. Once received, newly purchased works will be catalogued ${ }^{27}$

The policy set by KFAC is perhaps most relevant to KMAC because their missions are similar, they collect the same objects, and are comparable in the size of their collections. Outlining what objects they wish to collect is important for Folk Art museums because there are so many types of art that could be labeled "Folk" and it is important to distinguish these items. The KFAC policy also addresses how to give objects an accession number and how to catalogue; this provision allows volunteers and interns working with the collection to have knowledge of documentation requirements. These are two essential guidelines to involve in a future policy for KMAC because there is a history of frequent turn-over in staff, volunteers, and interns.

What the above examples demonstrate is the detailed process that each museum goes through before accessioning an object into a collection. There is a lot of time and energy invested in acquiring objects for museums because the museum wants to ensure that the works acquired both support the mission, complement the other objects in the collection, and limit risk. The Curators assemble the information about the provenance of the objects, organize any information the donor or seller can provide, and review condition of the object. Then a committee of the Board reviews the facts before deciding whether or not to recommend to the entire Board that an object should be included in the permanent collection. The processes that these museums take are good to note, because each is slightly different, though most of them have the same general system of gathering

\footnotetext{
${ }^{27}$ KFAC, “Permanent Collection Policy”, 4-6.
} 
information on the object, having the object proposed by the Curatorial staff, and then approved by Director and/or Board of the museum. The policies discussed here are excellent examples of what KMAC should consider in the future. As three of these museums (The Walters, Guggenheim, and The Speed Art Museum) are all American Association of Museums (AAM) accredited institutions, these examples show the proper and accepted way of collecting in the museum. If these had been studied by the Board

and staff prior to creating their policy, KMAC could have better accessioned objects into the permanent collection, however creating a comprehensive policy to include these points will allow KMAC to formalize their operations, and improve them for the future.

\section{Developing A New Policy}

In looking at KMAC’s drafted collection policy in comparison to the other museums, there are some noted differences. When KMAC is in the process of accepting an object from gifts or bequests, there is no involvement of the Board or an executive committee. In fact, it is stated in the drafted policy, that no one other than the Curator or Director can be involved in this process, which differs in comparison to the examples listed earlier. Since there has been no accession policy formally accepted, it has created issues within the collection. The Board is responsible for the finances and well being of the museum and its collections, however they are not involved in deciding what donated objects are accessioned into the collection. This has potential to cause future problems with proper storage, financial ability to care for the objects, and complete documentation of the objects. While both the Director and Curator may have the best intentions in 
accepting artwork into the collection, there are still considerations that can be raised about objects if they are presented to the Board.

Along with the disconnect between staff and Board, there have been differences in how the objects are prepared for accession. All of the examples discussed above relate to how the Curator is supposed to prepare documents on the object(s) proposed for accession, including information such as provenance, donor/seller, exhibition history, publications, any restrictions listed by donor, any appraisals, proof of ownership/title, and relevance for the collection. Having the Curator, or other staff and volunteers, prepare documentation before the object is accepted allows the museum to start developing information about the object and the artist, along with the other places the object has been over time. Information such as this should be researched before acquiring the art to help both the staff and Board determine whether or not the object should be in the collection.

Due to the issues with the process of acquiring objects, a new procedure should be developed to synthesize a new KMAC policy with the most desirable aspects of the other policies discussed. One of the key reasons to create a new policy is the lack of communication between staff and Board when it comes to acquiring donated objects. For example, if the Curator and Director must present the object to the Board before approving them for the collection, there would be a greater amount of research including tracking provenance for the object. This has not happened at KMAC recently, it is solely the responsibility of the Director and Curator to accept donated objects to the museum. If objects were proposed to the Board there would be the expectation of research regarding 
the artists, the objects, and how the specifically donated objects will fit into the collection. A more formal process would raise the level of scrutiny in potential purchases and handling of donations. Some of the more well-known Kentucky artists have biographies in the museum files but many other artists represented by one or two objects have little to no information (i.e. Charles Rolwing). Along with these issues, there are problems with lack of documentation of donors, artists, and object provenance files. These problems were due mainly to the fact that there has been no policy or a procedures manual formally adopted that outlines how objects would be accepted and documented at the museum.

When developing a new policy for KMAC the essential areas to be included are the mission, the objectives for collecting, the analysis of objects before they are accessioned, the roles in which the employees and the Board of the museum participate when it comes to acquiring new objects, and the processing of objects into KMAC's system of cataloging and record-keeping. In the drafted policy each of these areas are inadequately covered. In correcting the problematic areas, employees and volunteers can keep better records of the future materials and objects brought into the museum. Located in the appendix is a recommended sample of the acquisition section of the collection policy for the museum (Fig. 3), including some of the original ideas and text from the previously drafted policy combined with this proposed version.

The suggested policy (Fig. 3) includes recommendations from the examined policies, as well as sections from the drafted policy written by KMAC. Procedures that 
are influenced by other policies are: assurance regarding what the museum will do with the objects it collects; exacting definitions of what the museum is looking to collect and how they acquire those objects; a process of acquisition that includes Board approval for objects donated to or purchased by the museum; necessary research made by the Curator before objects are proposed to the Board; inclusion of how to add objects into the catalogue and filing system; and temporary loan numbers. As for the procedures added, which are not in the example policies but are important to note for KMAC specifically, are in the sections regarding the origins of donated objects made for sale through the retail component. Before deciding to have a permanent collection, KMAC began as an institution that sold exclusively Kentucky artists works in the shop and held temporary exhibitions in the galleries. It is important to note this area of the museum because it is a critical part of how the museum functions daily.

Having a new policy should help with the organization of files for future objects that are donated to or purchased by KMAC. Currently, the correspondence between KMAC and the donors are all kept in one file for the organization of the catalogue. These letters were once scattered amongst old physical files kept by the Curator, but found during the process of searching files for information about the objects in the permanent collection. Establishing a new policy, along with a procedures manual, will help start a process of donor files where the correspondence between donor and the museum is organized, allowing for future staff and volunteers to locate the information. A new policy will help with the establishment of artist files containing biographies, exhibitions in which the artist has participated, the catalogue form of their artwork in the permanent 
collection, and other relevant details. Here is an example of what Charles Rolwing's file would look like:

Figure 2 Charles Rolwing's Artist File

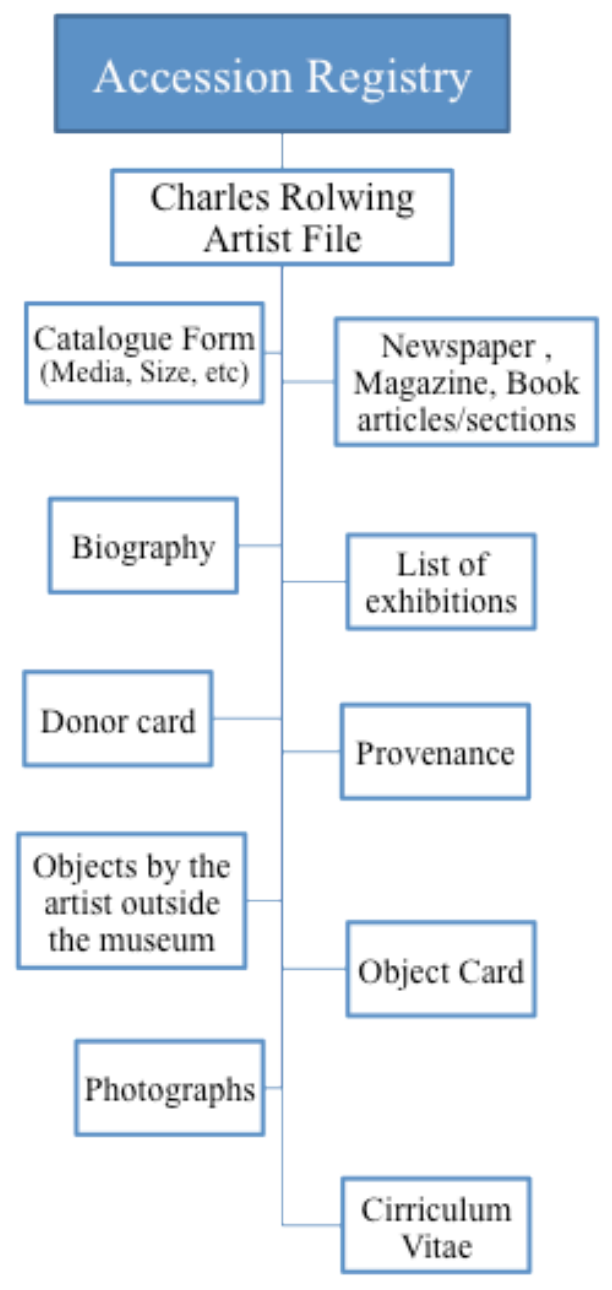

Due to the KMAC collections policy not being formalized, it has been a difficult process to find information on artists who had no files or limited documentation in the collection. It has been minimally useful to find information on a few artists to search 
through folk art encyclopedias ${ }^{28}$, but many others have little to no information available. Having a catalogue or a data management system to organize a collection assists with the documentation of the objects in the collection, along with helping the staff create future exhibitions at the museum. This information should be a standard, which will propel the study and exhibition of Kentucky Craft in the future and can be seen as a major contribution KMAC can make to the field of art and craft. It is important for museums like KMAC that focus on regional artists, to keep these records because they are potentially one of the only sources of information about these artists. The new collection policy will help lay a foundation for future research and scholarship at the museum, and in the community at large.

The next chapter discusses the process to find information on artists and composes an organizational system for the managing collection of a small museum.

${ }^{28}$ Betty Carol Sellen and Cynthia J Johanson, Self Taught, Outsider, and Folk Art: A Guide to American Artists, Locations and Resources (Jefferson, N.C.: McFarland \& Co., 2000); Betty Carol Sellen and Cynthia J Johanson, 20th Century American Folk, Self Taught, and Outsider Art (New York: Neal-Schuman, 1993). 


\section{ORGANIZING THE PERMANENT COLLECTION}

During my time working on organizing the permanent collection at the Kentucky Museum of Art and Craft, I found that there was a drafted collections policy that the board never adopted. Without a policy in place, the museum's collection was not properly organized or maintained. How the collection should be managed, such as the numbering, handling, and photographing of objects, is noted in academic texts and is in place in other museums' permanent collection policies. The system in place at KMAC when I began working there was primarily composed of annual audit lists made up by the Curator for the C.P.A. There was some organization of large donations made to the museum with a catalogue-like form KMAC called a "Donation Log” (Fig. 4). This form

included some important information: Inventory Number, Artist, Title, Media, Date, Size, Insurance Value, and Condition Notes. While some of the essentials needed for a catalogue sheet are included, the form does not have enough necessary information about the object. Additional information would provide a better overall view of the object and its origin. It is necessary for any small museum to have a catalogue form and accession number system, especially when the permanent collection contains over three hundred objects.

The process I used to change the documentation of the permanent collection during my internship is reflected in my recommended changes to the policy in the prior 
chapter. I will describe both a manual entry and a data entry process to document the collection. The one I used, and for which tools were available at KMAC, was a manual entry system.

\section{Manual Catalogue Entry}

In order to create more thorough records of KMAC's permanent collection, I developed a master inventory list with an Excel spreadsheet (Fig. 5) that included every object that was either documented or known to be a part of the permanent collection. This document included: Artist Name, Object Title, Material, Measurements, Value, Acquisition (How and When), Donor, and Location. This list of all the objects helped determine what information was missing on specific works. The hardest part of making this master list was determining when objects were purchased or donated to the museum. For some of the objects, there were dated donation letters or lists, but for many it was impossible to find a date of a donation. Due to the difficulty of dating the acquisitions, the best initial way to organize the objects was in alphabetical order by artist's last name. By organizing the collection in this manner, employees and volunteers could track the objects once the new catalogue was created. While this was a temporary practical solution, there is always room for improvement. It is possible that new information will surface later to help identify when purchases and donations were made at the museum. The process of organizing will always be an ongoing task managed by the staff and volunteers. 
Once the master inventory list was created, the next step was to develop the new catalogue. This task was difficult due to the lack of a data management system, so the only option was to create a form and type each page for the catalogue. Examining books discussing registration and collection management methods, as well as other museums' catalogue forms was helpful in shaping the catalogue. One of the first topics encountered in these references was that of the accession numbering system. There are three different systems, each based upon how many numbers used. The first is a single-number system, the second a two-number system, and the third a three-number system. ${ }^{29}$ The singlenumber system was an original museum method, but has now fallen out of usage. The two and three number systems are most common today. The two-number system is based upon year of donation and the number designated to an object. This system does not give information about which part of the year the object was donated, or who the donor may have been. It has been noted that this is the best system for smaller museums. ${ }^{30}$ The three-number system is one that notes the year of donation, which donation, and the number assigned to an object. In this system the museum can identify the specific donation/donor by giving them separate donation numbers. This system is helpful for larger museums, or museums which receive several donations in each year.

It can be difficult to determine which numbering system would be best for a museum. The first system applied for KMAC was a two-number system because some objects were dated only by year, and not an exact month they were donated. There was also the problem of the objects in which there was no donation or purchase year

${ }^{29}$ Daniel B. Reibel, Registration Methods for the Small Museum, Fourth (Lanham, MD: AltaMira Press, 2008), 40-42.

${ }^{30}$ Reibel, Registration Methods for the Small Museum, 43 
attributed to them. One suggestion found was to accession unknown objects, as one large group by using the current year that the catalogue is being worked on. ${ }^{31}$ There are two options for how to list the year as the first number: one can use a partial year number, such as 1996 would be 996, or list the year in its entirety. The best choice seemed to be to list the year in its entirety because it would be the easiest to understand if volunteers had to handle the accessioning of objects. ${ }^{32}$ Then for the second number the objects were arranged alphabetically by artists' last name for the order in which the objects got the second number. One thing that helped this process was that the master inventory list was already created, which listed all the artists in the collection alphabetically. Then another list was made arranging objects by year of donation (Fig. 6). This helped arrange the objects by year first, then alphabetically within each year, allowing for the two-number system to easily come into existence.

After developing the two-number system, it was presented to the Director who suggested a three-number system would be better. The change between a two-number system and a three-number system was difficult because of disparity in records: some were more organized for some objects, and barely in existence for others. Most years, the museum had only one major donation, though there were multiple purchases or donations. The knowledge of multiple donations a year led me to go through the documents again to find any time stamps for specific donations. Letters of communication to donors were found, and it was decided that this would be the time stamp of recognition by the museum of when the specific donation of an object occurred.

${ }^{31}$ Reibel, Registration Methods for the Small Museum, 45

${ }^{32}$ Rebecca A. Buck and Jean Allman Gilmore, The New Museum Registration Methods, (Washington D.C: American Association of Museums, 1998), 43. 
With the discovery of these letters, the donations were put into the order that they came into the museum. For example, 2008 was a large year of donations to the museum. By finding letters written by the previous Curator to the donors, the donations could be arranged in numerical order according to when they were donated to the museum. When giving a donation a numerical number, or the second number in the three-number system, it allows for those looking at the catalogue to know that objects were a part of a specific donation. As for the objects that had no listing of a specific year of donation, the year that this catalogue has been worked on was chosen as the year to group them under. As for the donor number, zero was chosen because they were donated or purchased at unknown times. The only time the accession number can change is if there is reliable documentation found, such as a donor letter, which confirms the true date in which the object was purchased or donated to the museum.

Having the accession number system settled, the next important thing to decide was what to include in the new catalogue form for the museum. There were elements from the "Donation Log” form the museum had (Fig. 4) that were important to keep, but there was more information that could be included. According to several sources ${ }^{33}$, the catalogue form should include: accession number, object name, classification, artist, object date, insurance value, where the object was made, techniques, materials, colors, style, size, description, donor, how the object was accessioned, date acquired, condition, location, picture, and who entered the information. When looking at other catalogue forms, the one that looked the most helpful to adopt for KMAC's new catalogue form

${ }^{33}$ Reibel, Registration Methods for the Small Museum, 61; Buck and Gilmore, The New Museum Registration Methods, 31; Robert G. Chenhall, Museum Cataloging in the Computer Age (Nashville: The American Association for State and Local History, 1975), 54-57. 
was from the Illinois State Museum (Fig. 7). The Illinois catalogue form was specifically for fine and decorative arts, which seemed most applicable to KMAC. From the Illinois form to the KMAC form, some of the same categories and order of the categories were adopted. Instead of having lines by the category (Fig. 7), there was a table created with the catalogue terminology on one side and an empty area on the other to fill in the necessary information. Another important thing to add to the new catalogue form was KMAC’s information at the top of the catalogue sheet, allowing anyone who was viewing the sheet to recognize that these objects come from this specific museum. The final form (Fig. 8) includes the museum's logo, contact information, the detailed information of each object, and an image of the object.

After creating the new template for the catalogue form, information was entered for each object in the collection. Once again the master inventory list was helpful in adding the basic information into the catalogue. The next thing to add to the catalogue, which was not in the master list, was the classification system of the objects in the permanent collection. The terms derived from the Getty standards are in the Art and Architecture Thesaurus ${ }^{34}$, which amongst museums is considered one of the highest authorities when it comes to nomenclature used to define objects. The classifications I used for KMAC are simple in comparison to the Getty, but this is necessary because there is a good chance that people not familiar with the nomenclature system will handle cataloging the permanent collection. The terms I chose from the Getty Standard for the catalogue are the only ones to be used. If the museum acquires an object that cannot be

\footnotetext{
34 The J. Paul Getty Trust. Art and Architecture Thesarus. The Getty Research Institute, 2000,
} http://www.getty.edu/research/tools/vocabularies/aat/index.html. 
classified under the determined list, they should consult the Getty Standard before adding more nomenclature.

The first term in the nomenclature hierarchy is designed to cover a broad enough range to include the majority of the objects in the collection, and more precise terms will follow. The first thing to look at was the material that the objects were made from (Fig. 9). These materials became the major headings; listed below them would be a more specific category by which to classify the objects. For example, objects made out of wood, there would be several subheadings such as carving, lathe-turned, and fabricated. Each of these subheadings beneath the main classification of wood allow for the viewer of the catalogue to have a better idea of the process in which the object was made. This manner of classifying the objects seemed most appropriate because museums focusing on craft and craft processes have multiple ways to use each medium. It is important to be as specific as possible. The classifications will help staff and volunteers with how the objects should be cared for and stored, the usage of objects in exhibitions, and suggest other ways of organizing the objects in the collection.

Once the catalogue was filled out with the information from the master list, research on the artist's birth and death dates and where they were from followed. Having these two elements of information help place both the staff and visitors of the museum into a specific time frame and place of origin for the objects they are viewing in the museum. It is important to give each object relative context when presenting them for public viewing. This led to research online and through books that discussed folk art and 
artists. As noted above, the most helpful were encyclopedias on Folk Artists by Betty Sellen and Cynthia Johanson ${ }^{35}$. These sources, along with a website entitled Detour $\mathrm{Art}^{36}$, were the most useful with the locations of artists and birth and death dates. While these filled in the gaps of information for many artists, there were still some objects whose artists about whom I could find no information on. Due to lack of documentation at the time I began working on the process, it was hard to find any history regarding many of the objects. One of those who fell to this category was Charles Rolwing. While I could find information on some artists that previously had no records at the museum, Rolwing was a reminder why it was hard to find any information.

\section{Computer Data Management}

One option of keeping records in the small museum is by having a data management system on the computer. This helps with keeping multiple records all in one area such as artist information, exhibitions in the museum, what objects were in the exhibitions, and donor information. Having a data management system can be helpful because it allows easy search around the information by artist, exhibit, medium, etc., instead of looking manually through many files to get the information needed. While having a manual back up is a good idea, the computer management system will help the staff and volunteers find information about the objects in a quicker manner.

\footnotetext{
${ }^{35}$ Sellen and Johanson, Self Taught, Outsider, and Folk Art; Sellen and Johanson, 20th Century American Folk, Self Taught, and Outsider Art.

${ }^{36}$ Kelly Ludwig, 2008, http://www.detourart.com/detourbook.html.
} 
There are several options in data management systems including software developed commercially and in-house at museums. The first thing to determine is how the information should be stored. There are three different database systems: Flat file, Relational, and Object-Oriented. A Flat file database keeps all the information in a single large table, a Relational database keeps data in separate tables, each "related" to the other by means of common field such as accession number or donor number, and an ObjectOriented database is a relational system that utilizes the same type of fields within the database and the application, removing the need for software to translate between the database fields and the output program. ${ }^{37}$

The next thing that is important to determine is that there is adequate computer capacity and systems to handle the data management process. There are commercially developed databases, such as File Maker Pro, SQL, and Access, which are worthwhile. These systems can be useful and may have some museum templates to work from, but a majority of the time the database must be adapted to the needs of the museum. Another option is to have a database made for the institution. This can be difficult at first and will likely require a software programmer to create the system for the museum. The benefit is that it will have everything the museum wants or needs for the time. The only downside to this system is that if the staff wants to share the information with a website, the public, or other institutions, it may be difficult for those with whom the museum is sharing the data to understand what they are looking at in the first place. The last option is to have a commercial collections management system, such as Past Perfect, that is made

\footnotetext{
${ }^{37}$ Rebecca A Buck and Jean Allman Gilmore, MRM5 Museum Registration Methods, 5th (Washington D.C.: The AAM Press, 2010), 161-162.
} 
specifically for cataloging and collections management use. The only downside to these systems is that they are very expensive in the beginning and can have some upkeep fees, but it will cater to the needs of the museum exactly.

Since KMAC did not have the data management systems in place, nor the financial ability to purchase a system, the manual catalogue was made for the time being. In my work on the catalogue, some of the artists were unknown and difficult to find among resources I had collected. One specific artist became the most intriguing when I stumbled upon the discovery that his son is also an artist. His name was Charles Rolwing, one of the artists in the collection upon whom there was no information in the files, other than discovering his name written incorrectly in other organizational documents when I went through measuring and photographing each of the objects in the collection. Mary Norton Shands and the Reverend Alfred R. Shands III, some of the largest art collectors in Louisville, had donated the sculpture by Charles Rolwing, along with many other objects in 2007. This donation by the Shands was documented in the older catalogue system, but outside of the basic information about the objects, there was very little on the artists and who they were. In the next chapter I will elaborate more on my findings on Charles Rolwing and the importance of this procedure for the collection. 


\section{UNEARTHING CHARLES ROLWING}

While working on the permanent collection at Kentucky Museum of Art and Craft, extensive research was needed on artists' pieces that had no documented information. One of these undocumented works of art was Charles Rolwing's piece, Angel (Fig.10 and 11). A small painted wooden sculpture held up by a metal rod placed onto a wooden base, it creates an illusion that the sculpture of the angel is floating. Other imagery that helps with this illusion is that the figure is reclined on an organic shape that many would conclude looks like a cloud. The figure contains female characteristics, such as enlarged breasts, curved buttocks area, painted fingernails, long hair, and is shown wearing high heel shoes. While the major characteristics of female anatomy are noted, there is no realistic human form detail such as her face, which does not include eyes, ears, nose, or mouth, as well as her body, where no musculature or bone structure is depicted. This female form was intriguing because the sculpture incorporates two types of imagery: an angel in high heels, and a cigarette, which together make an unlikely pairing. This intriguing combination of imagery led to my research to find more about the artist, not only for the museum, but also for my own curiosity.

Working on the catalogue page for Rolwing's Angel (Fig. 12) was the first time I had come across his work. It was difficult to fill in all the information such as where he 
was from, when he lived, or anything as a background for the piece because there was no documentation or artist files at the museum. This led to the research that I have conducted over the last year to find information on Rolwing. While searching on the Internet, it appeared that the artist had a website. I e-mailed asking if the Angel piece was the artist's and if he could give more information about the work. It turned out that the Rolwing I had contacted was the son of the artist who created the work that KMAC had in the permanent collection. This in turn led to being able to connect with the artist's family and others who knew the senior Charles Rolwing during his lifetime. Unfortunately he had passed away in May of $2008^{38}$. His family talked about who he was as an artist, which created connections to other people to see if they knew of him or had his art in their collections.

\section{Interviews and Contacts Made}

After the initial contact was made, the first task was to speak with the family of the elder Charles Rolwing. The first interview was with his two daughters, Lisa Whidden and Julie Rolwing. They revealed much about him through newspaper clippings along with exhibit cards they had from a select few galleries. They were able to provide personal information that showed he was really passionate about his work, while at the same time very introverted and shy. ${ }^{39}$ Through the newspaper clippings there was more information about the different media he used, where he showed his work, and a little more about his personality. The connection with the daughters led to a meeting with their mother, Dee Rolwing, who still had many of her husband's works at her home including

\footnotetext{
38 "Obituary: E. Charles Rolwing Jr.," The News Standard, 30 May 2008

${ }^{39}$ Lisa Whidden and Julie Rolwing, interview by Elizabeth Rue, Louisville, KY (23 September 2011).
} 
selections of his watercolors, wood block prints, small wooden sculpture, an oil painting, and a metal sculpture. Seeing these other works in comparison to Angel was intriguing and offered a better grasp of his style of painting and sculpture.

After meeting with the artist's family and seeing more of his work, I began an exploration of the galleries and other places that would have his artwork. This part was difficult because most of the places where he had shown his work in the past are not in existence anymore, and have currently been replaced by other businesses. One of the galleries whose owners I was able to get in contact with was that of the Swearingen-Byck gallery. Both Carol Swearingen and Marlene Byck, currently Marlene Grissom, had pieces of Rolwing in their own collections and were willing to meet for interviews. My grandparents Edwin Perry and K Shaver also have two pieces, one at their home in Louisville and the other in their vacation home in Savannah, GA. The last person I was able to meet with who knew Charles Rolwing was Cheryl Plain, who worked with him at Fort Knox. She also had a piece of his at her cabin, and was able to meet for an interview as well.

\section{Dead Ends in Research}

While there were numerous people with whom I could discuss Charles Rolwing and his work, there were also many dead ends. The first area that I tried to check was different museums in Kentucky that collected Kentucky artists, including the Kentucky Museum, Owensboro Museum of Fine Art, Kentucky Folk Art Center, and the Kentucky Arts Council. The first place, The Kentucky Museum is located in Bowling Green, KY on the campus of Western Kentucky University, and they are known for having 
decorative and fine art, textiles, and archeological objects from around Kentucky. The second one was the Owensboro Museum of Fine Art in Owensboro, KY, with a collection that contains Kentucky art, as well as European and Asian art. The third is the Kentucky Folk Art Center in Morehead, KY, connected with Morehead State University and very similar to KMAC in its focus on folk art of Kentucky artists. The last place I contacted was the Kentucky Arts Council, which, though not a museum, still has a lot of information and a collection of works by Kentucky artists. I contacted each of these organizations via phone and e-mail and each of them told me that they had no information on Charles Rolwing.

Another set of organizations checked were Spring Hill College, Hilliard Lyons, and PNC Bank. The first place was Spring Hill College, where Charles Rolwing earned his bachelors in painting; I had hoped that they might have information on him since he was at one time a somewhat popular artist. But they could provide nothing more than his degree and the year he graduated. The next two places were Hilliard Lyons and PNC Bank, which have been known to purchase art from local artists. Each of these places had no information. This was disappointing because the images and works viewed were so wonderful, yet no one had any information on him. There are a couple more places where information could be found on Rolwing including, Kentucky Guild of Artists and Craftsmen, St. James Art Fair, and Brown Forman, each of these organizations would be excellent sources to investigate in the future. 


\section{Biography and Art of the Artist}

Through my research, primarily through family and newspaper articles, I have been able to assemble a fairly complete biography for the artist. Charles Rolwing was born in 1935 in Charleston, MO where his father was a well-known doctor. He graduated from Spring Hill College with a B.F.A. in painting in 1957, and married his first wife, Dee. After graduating from college, they moved to San Francisco, CA, for three years at Travis Air Force Base to fulfill his draft obligation. Then after his time at Travis Air Force Base, they moved to Ft. Detrick in Frederick, MD. At Ft. Detrick Charles had his first Arts and Crafts Director job, and a few years after that, moved to be the Arts and Crafts Director at Ft. Knox in Kentucky for 22 years. He was not a large fan of the military, but felt it would be one of the better jobs to have being employed by the government. After his time at Ft. Knox, Charles married his second wife, Frances, and owned Excell Printing in Radcliff, KY, for 21 years. Charles passed away May 20, 2008, in Radcliff, KY.

Once contact was gained with Charles’ family it was discovered that he worked in several media besides wood including: acrylic, oil, watercolor painting, metal, and wood block print. This seemed logical due to his time as an Arts and Crafts Director at Ft. Detrick and Ft. Knox. During his time in San Francisco, the counter-culture movement was evolving in California and had an impact on Charles as a person as well as his passion for becoming an artist. Though he did not participate in many activities associated with hippies, the experience, along with his passion for becoming an artist, had 
an impact on Charles as a person. While he did not have any specific period in which he did art, for example working with only painting or only sculpture for periods of time, you could say he had some large influences from his life in his art. Another thing that helped Charles develop his art was access to various materials at Ft. Knox, as well as the opportunity to learn from the different faculty that taught in the department.

The first things that Charles made and sold were pen and ink drawings and woodblock prints, in the late 1960's. At the home of the first wife Dee, there are several pen and ink sketches from a later series of Angels he did in a sketchbook (Fig. 13 and 14), and a few wood block prints that were simple black figures on white background (Fig. 15 and 16). After these were completed, he worked more in painting and wood sculpture. Aside from learning painting in college, it seems that he was self-taught as a wood sculptor. While he made wooden sculptures similar in size to Angel, he was also known for making life size and bigger sculptures of women (Fig.17 and 18). In the first image shown, there are three of his women sculptures surrounding Charles giving a good indication of size. The sculpture to Charles' left has been referred to as “The Crank Lady”. ${ }^{40}$ Another example of these large women is the sculpture owned by Marlene Grissom (Fig. 19). This piece is four sided, and has a different woman painted or drawn on each side of the rectangular sculpture. The sculpture is also divided into three parts vertically, allowing for the head and the bodies to be interchangeable amongst the four painted and drawn on the sculpture.

\footnotetext{
${ }^{40}$ John Christensen, "Ladies Man: How artist Charles Rolwing found happiness and success in the arms (and legs and heads) of wooden women,” The Courier Journal \& Times.; Sarah Lansdell, "Can canvas and metal replace Rolwing's old flames?,” The Courier Journal \& Times, July 1972.; Lisa Whidden and Julie Rolwing, interview.
} 
During the 1970’s and his time at Ft. Knox, Rolwing had multiple phases of painting that overlapped. One phase was portraits of Johnny Cash, and in 1970, he had a show of painting and sculptures of Johnny Cash both at the Huntsville Art League and Museum in Huntsville, AL, and one later at the Port O’ Call Gallery in Louisville, KY. Another phase was his abstract paintings, mainly consisting of primary colors and black lined organic shapes (Fig. 20 and 21). According to Cheryl Plain, the black lines of these paintings were squeezed straight from the bottle onto the painting. ${ }^{41}$ These were some of his most popular paintings and at one time were located in several businesses and hospitals downtown, according to the Rolwing family. These were so popular that both Carol Swearingen and K Shaver still own copies of the abstract pieces. Mrs. Swearingen’s piece (Fig. 22) followed the typical primary color and black line arrangement, while Mrs. Shaver’s piece (Fig. 23) involved many shapes and arrangements of color unseen in the previous examples. Rolwing made a trip out west during his time at Ft. Knox and after which he began to paint western landscapes. At Dee's home there were two examples from this phase of work, the first a large landscape painting (Fig. 24) and the other was what Rolwing called "Six Packs,” which consisted of six small sketches on paper, of Western Landscapes (Fig. 25). He also worked regularly in watercolor (Fig. 26 and 27) and most of the examples seen in this medium had women as the main subject matter.

${ }^{41}$ Cheryl Plain, interview by Elizabeth Rue, Louisville, KY, (March 17, 2012). 


\section{Art Analysis}

When looking at Rolwing's art as a whole, his primary subject matter were generally: abstract, women, angels, musicians, and landscapes. Each of these subjects had some influence from his life experiences or people he admired. I don't think it would be easy to classify his art as a whole, there are so many components and influences that there is no one thing you could say is Charles Rolwing. He was a sculptor, a painter, and printer, few artists can be talented at whatever medium they set their mind to, this is a task not well executed by many. Could this possibly be a downfall of his artistic success? This will never be known, but the small commercial success that he did have during the 1960’s and 1970’s made him popular enough for important collectors in Louisville, KY such as Mary Norton Shands and Reverend Alfred Shands, to purchase his work and donate it to the museum.

As for what directly influenced each subject that he used in his art, not all of the answers will be known, but some were made apparent through interviews with the family and newspaper articles discussing the artist. When it came to his female figures, their long legs, arms, hands, and nails were an influence from his first wife, Dee, who has all of these characteristics in real life. As for the abstract painting, Picasso influenced Rolwing and on several occasions it was mentioned that he really admired the artist and his work. ${ }^{42}$ He made his works on musicians, such as Johnny Cash and June Carter,

${ }^{42}$ Cheryl Plain, interview by Elizabeth Rue. Dee Rolwing, interview by Elizabeth Rue, Louisville, KY. Lisa Whidden and Julie Rolwing, interview by Elizabeth Rue. 
because he was a huge fan of them and listened to their music while making art. ${ }^{43}$ Lastly his western themed paintings were made after a trip he made out west with a friend and explored the landscape and the social atmosphere there. As for the Angel subject matter, I was not able to discover why he used this theme in his works but Angels did appear in both painting and sculpture works of art.

While Rolwing worked with several subjects and media, an interesting comparison to make would be Pop Artist Marisol Escobar. She was working during the same period as Rolwing and they have similarities in their works of art. They both composed artwork that reflected interactions in their lives, and worked in threedimensional media such as wood and metal. The best comparisons to make would be between their wooden sculptures that are life size and block like figures with painted clothing and stylized features of people on the wood. Rolwings' large female sculptures like the Crank Lady (Fig. 17) and the Four Women (Fig.19) would be good examples to compare to Marisol’s Dinner Date, 1963 (Fig. 28). While Marisol’s work is an entire setting rather than just the sculptural piece, the two figures have some of the same features as Rolwings’ female sculptures.

After looking at all of Charles Rolwing's works alongside the Angel work in KMAC’s permanent collection, I would recommend that this work stay in the collection. I believe his wooden sculpture pieces like Angel and the large women he made would be good additions to the permanent collection. Having a collection policy with a plan that assess the strengths and weaknesses of the collection with a plan that corresponds to the

${ }^{43}$ E. Charles Rolwing III, interview by Elizabeth Rue, Louisville, KY (21 February 2012). 
mission would be helpful guideline to use to base this assessment and recommendation. A large portion of the collection is filled with woodcarving, lathe-turned wood, and fabricated wood. Having Rolwings’ work along side other works by Kentucky folk artists is appropriate because his works are made from the same media, as are many of the works mainly displayed in the permanent collection. The more diversity in examples of a medium a museum can provide will give the visitors, especially those who come regularly to the museum, the more objects to enjoy, as opposed to the same selection of objects every time. Another reason for the appropriateness of Rolwing's work in the collection is that he is an artist who made his art in Kentucky, demonstrating artistic diversity, and possibly create opportunity for artists who are lesser known in Kentucky. 


\section{CONCLUSION}

Working with small museums and their collection policies can be a challenging undertaking, especially if the Board or staff has not formally developed an effective way to maintain the permanent collection. It is important for each organization to develop a clear and understandable policy that outlines the organizational procedures and processes in the acquisition of new works for the permanent collection. Having a system of checks and balances between the Board and the staff of the museum is also an important step, giving the Board of the museum final say on what is accessed into the collection. It is the responsibility of the Board to oversee the accession process of the permanent collection. This ensures that the policy has been carried out properly and fulfills the mission and values of the museum.

After my arrivial at KMAC to work on the permanent collection, it was apparent that there was no set system of how to organize the collection. Objects were in several locations around the museum, instead of one controlled storage area; physical and electronic files and documentation were scattered; and there was no cataloging system to organize the collection as a whole. Once I was discovered that there was no permanent collection policy officially embraced by the museum, it was easier to understand why the museum was in this condition. This prompted me to look at other museums' practices in documentation of works considered to be in the permanent collection. The practices 
outlined by other museums me determine out the best way to assimilate documentation of objects and artists. This led to the research and organization of documents and objects in the permanent collection.

In my research it has become evident that KMAC, like many other small museums, may not have the experience or resources to initially undertake the development of a comprehensive record of the permanent collection. In working on cataloging the permanent collection, it became clear that developing a new collection policy using examples from other museums and accredited resources would lead to more effective record keeping and easier management of the permanent collection. There had been no consistent research conducted before the objects were acquired into the collection. There were exceptions for those artists who are better known in Kentucky, including Marvin Finn, Minnie and Garland Adkins, and Linville Baker. On a larger scale they are lesser-known artists, despite being importantly contained within the KMAC collection. The sample policy proposal made for KMAC would allow for a better process in the future to acquire works, and will likely make it apparent that some of the works could be considered for deaccessioning from the museum. The policy would solve the issues with cataloging and giving the objects a clear accession number. If KMAC implements the policy proposed, or one similar to it, the museum would be in far better shape to collect for the future.

Another issue that KMAC faces, along with other small museums, is the lack of space for storing the permanent collection. Currently the objects are stored in offices and 
closets around the museum. KMAC should plan for space to store the permanent collection, whether they designate an area within the museum or find an off-site storage space. This is an essential part of the decision to acquire works at a museum. If there is not adequate amount of space in which to store works, or the financial ability to make it possible, then it should be determined if the item should be kept in the permanent collection.

I recommend that a collection policy be adopted by the museum soon. While in my work there, I was able to place the objects into an organized format, there should be an officially approved method in which information and documents are gathered by the museum. Having a policy, along with a procedures manual, will help employees and volunteers in the future collect, in the appropriate way, relevant information about the objects donated to or purchased by the museum. It will also help with the development of relationships with potential donors, because if the collection is organized and cared for properly, the museum is seen as more credible and a place where money and time can be invested. Until the museum has adopted such a policy, I suggest it would be prudent to not actively solicit donations or make any purchases, until a policy can be adopted. Accepting objects would be unfair to both the donor and the museum because there is no set direction in how to handle the objects properly, there is not enough staff or volunteers to help organize the objects correctly, and there is no adequate and appropriate storage system to care for the objects once they arrive at the museum. 
Once a policy is adopted, another recommendation I suggest is that a computerbased data management system be implemented. If the museum becomes financially able to purchase the software and educate staff on using a data management system, the improvement would be significant. This system would help assimilate all the known documentation of each artist and the objects at the museum into one accessible place. It would help with the development of future exhibitions, such as being able to create searches of objects by area, media, or any other relevant information for a planned exhibition. This system would help the staff have easy access to all the records and be able to share the records with other institutions or people if necessary.

As for Charles Rolwing, even though he is now a relatively unknown artist, there are still good reasons why his work should remain in the permanent collection. One reason is that at one time Rolwing did have a successful fine art career in Louisville and with additional research that would surely locate more of his work around the state of Kentucky and beyond. Another reason to retain Angel in the collection is that as a wooden sculpture, it aligns with a significant portion of the objects at the museum's permanent collection of woodcarvings, wooden sculpture, or lathe-turned wood. As a self-taught wood artist, Rolwing is consistent with many of the artists in the collection as well, because of their self-taught or “outsider” backgrounds. Additionally, the subject matter of the sculpture is important in its relevance to Kentucky culture. First, having an angel as the figure is common in Kentucky, being a place influenced by religious beliefs. Second, there is the cigarette held in the figure's hand. While it was made at a time when people were more likely to smoke, there is also the consideration that tobacco is a major 
cash crop for the commonwealth. Having the Angel sculpture represent these two common themes for the commonwealth of Kentucky makes this sculpture important to the collection. Furthermore, Mary Norton and Reverend Alfred Shands, who are some of the most significant collectors of Contemporary and Folk Art in Kentucky, donated this work. Lastly, the research that has been done on this sculpture has led to more significant work being identified and found in important private Kentucky collections, which could be targeted additions to improve the permanent collection.

I had many successes in researching Charles Rolwing, and having the permanent collection policy via the recommended suggestions will currently allow for the "unearthing” of Rolwing. Though undoubtedly more information could be found on him and his work, Rolwing is an excellent example of how artists who were at one time a success later become unknown to the general public. It is an important role for museums like KMAC to maintain extensive records on the legacy of such artists. These institutions and their collections are the only places that keep the history of the cultural legacy of artists such as Rolwing. The lesson for KMAC, and any other small museum, is that accurate record keeping is crucial. Each artist should have as complete a record as possible in order for the work in the collection to be useful for future audiences, whether for research, exhibitions, education, valuation or other unforeseen uses that may occur. To earn AAM accreditation and respect of the museum community, all museums should have a thorough policy and a strong set of staff, volunteers, and interns to carry out the proper way to manage museum holdings. 


\section{REFERENCES}

Abby Aldrich Rockefeller Folk Art Center. American Folk Portraits: Paintings and Drawings from the Abby Aldrich Rockefeller Folk Art Center. Boston: New York Graphic Society, 1981.

“Arts and Crafts Fair Enjoys Success.” The Turret, November 1971.

“Bored? Develop Hobby Crafts Dir. Can Help You.” The Turret, February 1969.

Buck, Rebecca A, and Jean Allman Gilmore. MRM5 Museum Registration Methods. 5th. Washington D.C.: The AAM Press, 2010.

Buck, Rebecca A., and Jean Allman Gilmore. The New Museum Registration Methods. Washington D.C: American Association of Museums, 1998.

"Registration and Cataloging." In Introduction to Museum Work, by G. Ellis Burcaw, 93101. Walnut Creek: Altamira Press, 1997.

Chenhall, Robert G. Museum Cataloging in the Computer Age. Nashville: The American Association for State and Local History, 1975.

Christensen, John. "Ladies Man: How artist Charles Rolwing found happiness and success in the arms (and legs and heads) of wooden women.” The Courier Journal \& Times.

Colonial Williamsburg Foundation. “Collections Management Policy.” Williamsburg, VA, 2010. 
Dudley, Dorothy H., and Irma Bezold Wilkinson. Museum Registration Methods. Washington D.C.: American Association of Museums, 1979.

Fahy, Ann, ed. Collections Management. New York: Routledge, 1995.

Grissom, Marlene, interview by Elizabeth Rue. Louisville, KY, (29-February 2012).

Huskey, Ken. "Knox Model Airplane Club Takes First Place at Indiantown Gap.” The Turret, June 1966.

Illinois State Museum. “Activities and Resources.” Museum Link Illinois. 2006. http://www.museum.state.il.us/muslink/pdfs/forms.pdf.

The J. Paul Getty Trust. Art and Architecture Thesarus. The Getty Research Institute, 2000, http://www.getty.edu/research/tools/vocabularies/aat/index.html.

Kay, Joan. "Wooden Figures Raise Eyebrows.” The Courier Journal \& Times, August 1969.

Kentucky Folk Art Center. "Permanent Collection Policy.” Kentucky Folk Art Center, 2009.

—. 2012. http://www2.moreheadstate.edu/kfac.

Kentucky Museum of Art and Craft. “Collection's Policy.” Louisville, KY: Kentucky Museum of Art and Craft, 2009.

—. Minutes of Meeting of the Collections Committee, Meeting of 19 November 2009.

Lansdell, Sarah. “Can canvas and metal replace Rolwing's old flames?” The Courier Journal \& Times, July 1972. 
Ludwig, Kelly. 2008. http://www.detourart.com/detourbook.html.

Marisol, Eleanor Heartney, and Judy Collischan. Marisol. Purchase, N.Y.: Neuberger Museum of Art, 2001.

Museum of New Mexico System. About the Collections. 2012. www.internationalfolkart.org/collections/aboutcollections.html.

—. "Collections Policy.” Sante Fe, NM: Museum of New Mexico System, 2009.

“Obituary: E. Charles Rolwing Jr.” The News Standard. 30 May 2008 .

Plain, Cheryl, interview by Elizabeth Rue. Louisville, KY, 17 March 2012.

Reibel, Daniel B. Registration Methods for the Small Museum. Fourth. Lanham, MD: AltaMira Press, 2008.

Rolwing III, E. Charles, interview by Elizabeth Rue. Louisville, KY, 21 February 2012.

Rolwing, Dee, interview by Elizabeth Rue. Louisville, KY, 6 November 2011.

Sellen, Betty Carol, and Cynthia J Johanson. 20th Century American Folk, Self Taught, and Outsider Art . New York: Neal-Schuman, 1993.

Sellen, Betty Carol, and Johanson J Cynthia. Self Taught, Outsider, and Folk Art: A Guide to American Artists, Locations and Resources. Jefferson, N.C.: McFarland \& Co., 2000.

Speed Art Museum. “Collection Management Policy.” Louisville, KY: Speed Art Museum, 2008.

—. Speed History. 2010. http://www.speedmuseum.org/history.html. 
Solomon R. Guggenheim Foundation. “Collections Management Policy.” New York: Solomon R. Guggenheim Museum, 2007.

Stief, Angela, Martin Walkner, Christoph Steinegger, Belinda Grace Gardner, Nelson Wattie, Gerald Matt, Kalliopi Minioudaki, et al. Power up: female pop art. Wien: Kunsthalle, 2010.

Swearingen, Carol, interview by Elizabeth Ru. Louisville, KY, 7 March 2012.

Walters Art Museum. “Accessions/Acquisitions Policy.” Baltimore: Walters Art Museum, 2006.

—. History of the Walters Art Museum. 2012. www.thewalters.org.

Whidden, Lisa and Julie Rolwing, interview by Elizabeth Rue. Louisville, KY, 23 September 2011. 
APPENDIX 
Figure 3 Recommended KMAC Acquisition Policy

KMAC Acquisitions Policy Proposal

The Kentucky Museum of Art and Craft exists as an institution that acquires, exhibits, preserves, and sells works of art and craft. The museum, will ensure that:

- The collections hold culturally and educationally valuable resources regarding local artists and crafts persons

- They are a resource for all those interested to know more about Kentucky artists, as well as other artists and craftspeople in the collection

- They are committed to handle, house, and protect the objects in a professional manner, and provide conservation treatments as necessary

- They are committed to collecting the categories of objects that support its mission

- They will provide arts and crafts in the gift shop made only by Kentucky artisans and crafts persons to help perpetuate the arts in Kentucky.

Mission:

The mission of the Kentucky Museum of Art and Craft is to support and promote Art and Craft excellence in Kentucky.

Objective:

The objective is to build upon the existing collection at KMAC with an emphasis on Objects made by Kentucky artists and Crafts people first and foremost. The museum will also accept donations from artists outside of Kentucky as long as the art is under one of the following criteria: Fine Art, Craft Art, Folk Art, "Outsider" Art, or Decorative Arts. This includes objects such as: Canes, Walking Sticks, Sculptures made out of any medium, Bowls, Furniture, Quilts, Woven Baskets, Paintings, Collages, etc.

Acquisitions:

The museum will collect objects in the following manner: Gifts, Bequests, Purchase, and Trade. The objects acquired by Purchase must be made by Kentucky artists or crafts people, while Gifts, Bequests, and Trade can be objects from outside of Kentucky as long as they follow the above criteria.

The following criteria must be met before acquiring an object:

1. The object must conform to the collecting policy.

2. The acquisitions will be supported by documentary evidence showing the ownership by the previous owner and effectively transferring the ownership to KMAC. 
3. The museum will not acquire works that are believed to be stolen, or illegally acquired by the previous owner.

4. KMAC must be in a position, both physically and fiscally to properly care for the proposed acquisition.

5. The acquisitions must be free from any donor-imposed restrictions

6 . The object should have documentary evidence of provenance and significance must be demonstrated

Acquisition Procedure:

In case of confusion the difference between Acquisition and Accession will be noted before the following steps are discussed. Acquisition means an object that is brought to the museum for donation, purchase, or for use outside the collection. Accession refers to the objects that have gone through Board approval and are designated to be in the permanent collection.

Gifts/Bequests:

1. If potential gift/bequest arrives at the museum before being accessioned into the collection it will be given a Temporary Loan (TL) number, so that the object will not be confused with accessioned permanent collection items.

2. The object will be reviewed by the Curator first and who will create documentation detailing:

- How the object fits into the mission and goals of the museum

- Provenance of the object (to make sure it is legal)

- Name and address of the present owner(s), the means of acquisition, and present location of the object

- Appraised value of the object, and the person who appraised the object

- Any restrictions or limitations noted by the donor

- Purpose of the object to be used in the future, statement of relevance to the collection

- Care, Conservation, and Maintenence needed for the object

- Costs related to the transportation of the object to the museum

3. Once this has be reviewed the Curator, they will give this information to the Director, and together they will present this information to the Collections Committee of the Board. This committee will review the information provided by the Curator and Director and will make their recommendations to the whole Board. The whole Board will make the final vote on donated items to the museum.

4. If donations contain multiple works, the Board can choose to accept some of the objects in the donation, and have the donor keep the other objects.

Gifts for Resale

1. The steps listed in Gifts/Bequests will also be done for those made for resale 
2. If the Board decides to not accession the object into the collection, but would find that the object had potential retail value and could be sold, meeting the standard for objects sold through the museum, then a letter must be written to the donor to ask if they approve of this action or would like the object(s) back.

3. If the donor approves of the objects being sold, the object will be given a new number that corresponds with the shop's numbering system and will not have an TL number, accession number, or catalogue page. If there is other art by this artist in the collection, have the work noted, photographed, and placed in the artist file. 4. The proceeds for these items will go into a permanent collection fund that will help purchase more appropriate works of art for the collection or finance the maintenance of the collection and the storage of objects.

Purchases:

1. The object will have to be reviewed and documented by the Curator should include the following information:

- How the object fits into the museum

- Provenance of the object (making sure it is legal and beyond reproach)

- Name and address of present owners, and the present location of the Object

- Sale value or recommended purchase price of the object

- Purpose of the object to be used in the future, statement of relevance to the collection

- Care, Conservation, and Matienence needed for the object

- Costs for purchase, transportation, and other related costs

2. Once the information is gathered the Director will review the object and determine if there are enough available funds and storage space before proceeding with purchase. Objects that are under $\$ 1,000$ will be reviewed by the Curator and Director for purchase. Objects over $\$ 1,000$ will be submitted to the Collections Committee and decided by the Board before a purchase is made.

Once the object is accepted into the collection then the Curator will give the object(s) an accession number and catalogue the object.

Exchanges:

1. Evidence of a fair financial basis, such as appraisal, must be demonstrated and documented before the Museum engages in any exchange.

2. The Curator will make their recommendations in writing for the exchange.

3. The organization with which the trade is conducted must show that they can properly care for the offered item(s) and must collect items of that type.

3. The organization must provide a statement, including information that they have full legal ownership of the item for exchange.

4.The recommendation will be presented to the Board for final approval

5. The Curator will maintain all records regarding all exchanges. 
Acquisition of Non-Collection Items

Non-Collection items such as reference materials, objects to be used for education purposes, equipment, supplies, and reproduction items are accepted donations to support and further the KMAC's objectives. Such donations shall be acknowledged by a letter of thanks to the donor. Non-collection items not to be accessioned, are regarded as expendable, and no commitment is made for their permanent use or preservation. They may be disposed of at the discretion of the Director and Curator.

\section{Cataloging the Objects}

Objects before Accession:

When objects are brought to the museum before being fully accessioned into the collection they will be given a Temporary Loan number. This number will include the following information: TL to designate that is a temporary loan, Year the object was brought to museum, the number deciding which loan this is (if there are multiple loans within a year), and then a number showing which item in the loan is associated with the object. For example:

\section{TL2012.1.001A-B}

This number tells us that the item is a temporary loan in 2012, that it is the first temporary loan of the year, and that the object is the first one in the loan. The capital letter is for when objects have multiple parts, and will go in alphabetical order from A to Z.

\section{Objects after Accession:}

Once the object is added to the collection it will be given an accession number similar to the Temporary Loan number. This number will start with the year of the donation, which donation in that year, and the number of the object within that donation. For example:

\subsubsection{A-B}

This tells us that the donation was made in 2012, it was the first donation of the year, and that the object is the first in the donation. Then if there are multiple pieces to an object, for example a Teapot there will be designation of a capitalized 
alphabetical letter for each part. This is helpful to designate objects to specific donations each year, especially if there are multiple donations made in a year.

Catalogue:

After the object has been given the accession number, the information gathered by the Curator previous to accessioning the object will be entered into a Catalogue Form, and will be assimilated into all the correct files electronically and in paper form.

There will be an artist file created for the artist, if there is not one already made. In the artist file there will be the catalogue form of the different works in the collection made by that particular artist, donor information and correspondence, biographical information, exhibits his artwork from the collection was in at KMAC and other museums or galleries, and any encyclopedia, book, newspaper, or magazine entries made that discuss the artist. This information will be stored in both a hard file and electronic file versions, so that the information is backed up in case one is to falter in the future. For example: newspaper clippings, book sections, catalogue pages, etc. will have a scanned copy in the artist file on the computer.

There will be a donor file created for each donor as they give work to the museum. This file will contain any correspondence between the museum and the donor, along with a catalogue form of each of the objects they donated to the museum.

For objects on temporary loan for exhibitions, they will be given a temporary loan number, as detailed above, and will have a catalogue page created for them. This will be paper clipped to any loan form that comes with the object to the museum. The forms will be all collected into one filing area maintained by Curator, and any volunteer or intern staff helping with the exhibitions. 


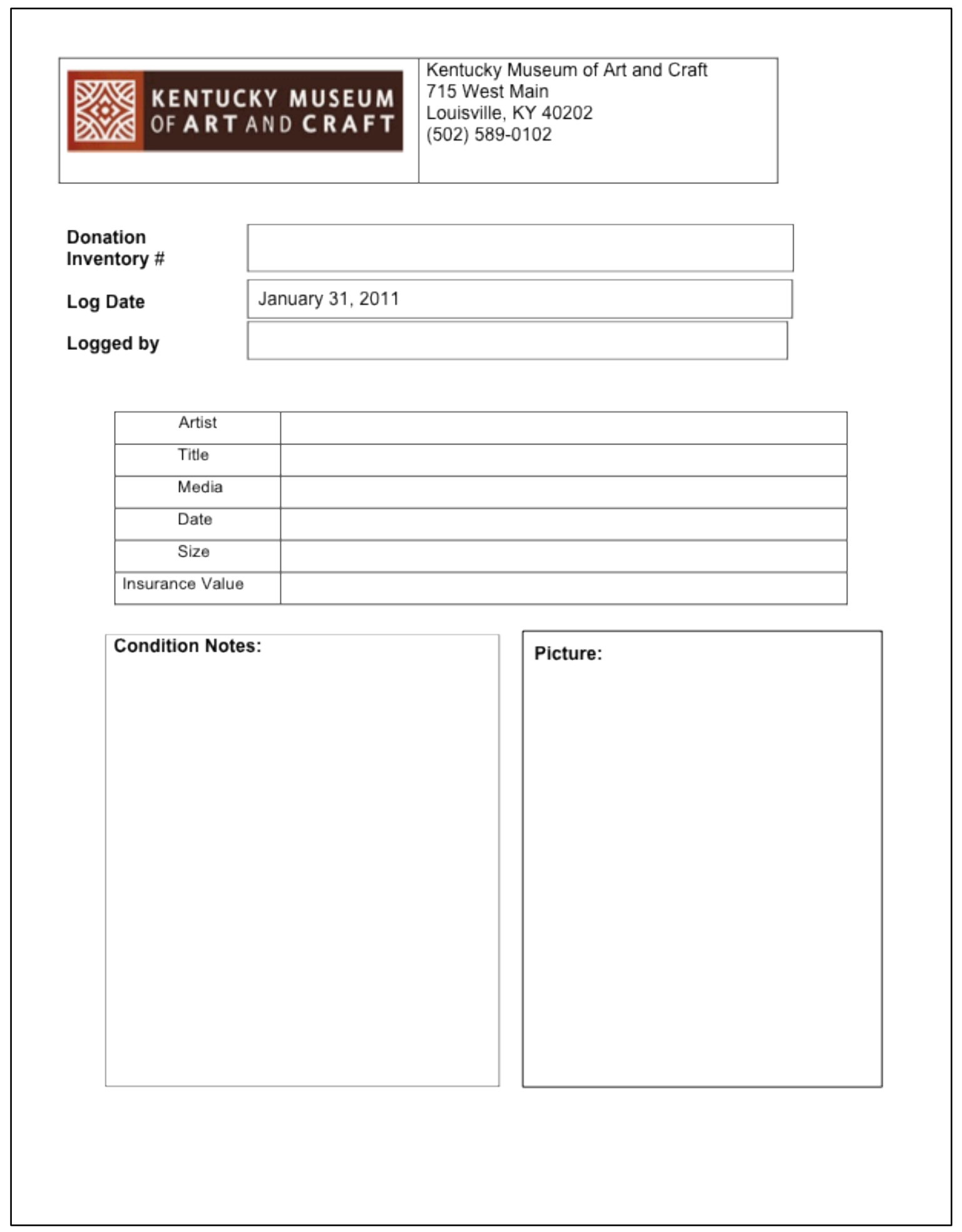

Figure 4 Original Catalogue Form 


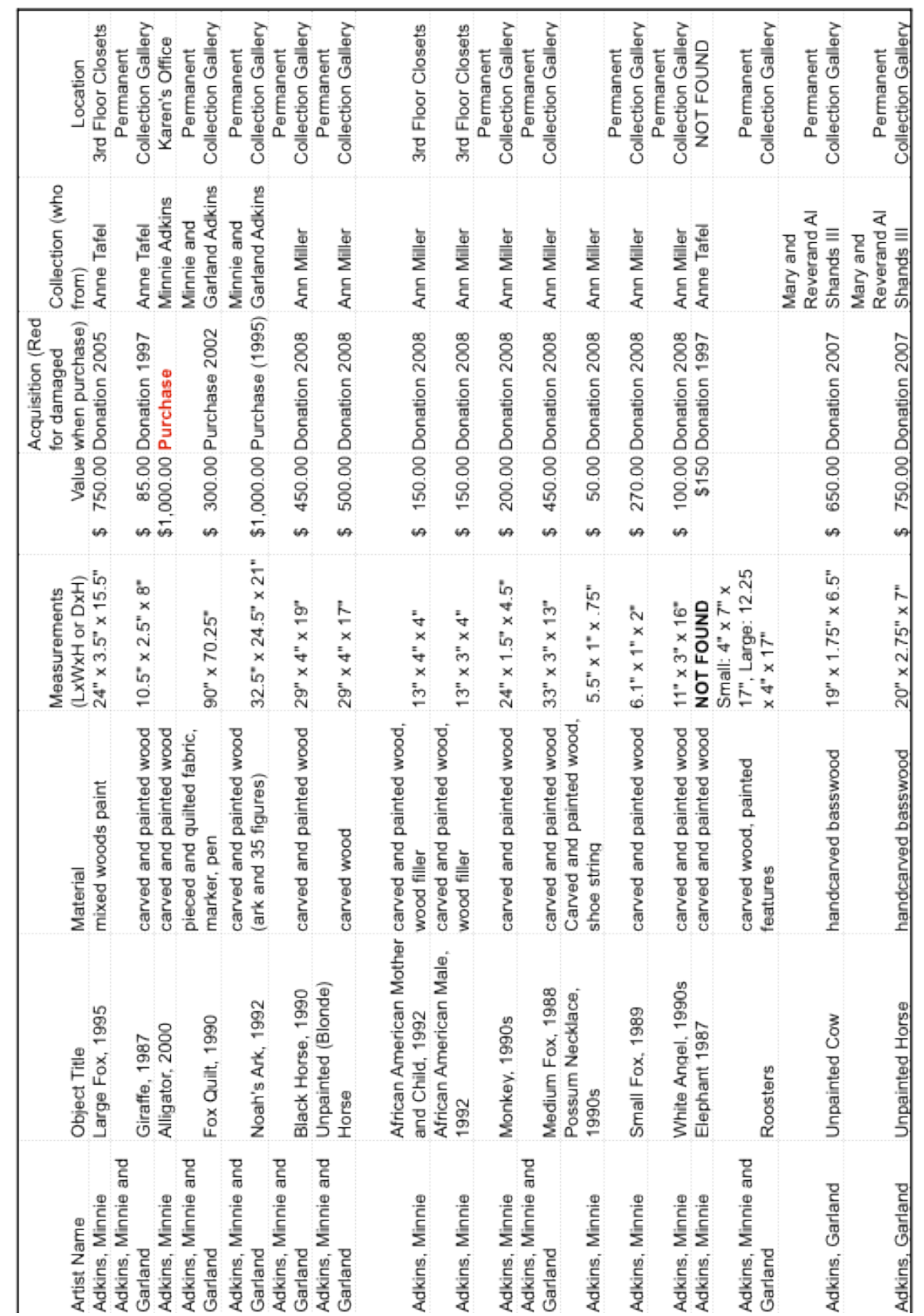

Figure 5 Example of Inventory Master List Excel Sheet 


\section{Collection List by Year}

1993

- Linvel Barker- Giraffe 1993.1.001

1995

- Minnie and Garland Adkins- Noah’s Ark 1995.1.001

1997

- Minnie and Garland Adkins- Giraffe 1997.1.001

- Minnie Adkins- Elephant (NOT FOUND) 1997.1.002

- Sarah Frederick- Lace Vase 1997.1.003

- Sarah Frederick- Three Small Gourds (NOT FOUND) 1997.1.004

- Noah Kinney- Fox 1997.1.005

- Erma "Junior" Lewis- Devil Boat 1997.1.006

- Erma "Junior" Lewis- Large Devil 1997.1.007

- Rude Osolnik- Small Box Elder Bowl 1997.1.008

- Rude Osolnik-Small Lace Redwood Bud Vase 1997.1.009

- Rude Osolnik- Small Lace Redwood Burl Bowl 1997.1.010

- Linvel Barker- Large Cat 1997.2.001

- Linvel Barker-Medium Cat 1997.2.002

- Linvel Barker- Small Cat 1997.2.003

1999

- Ronald Cooper- Wicked in Hell 1999.1.001

- Marjorie Freund- Kith and Kin Quilt 1999.2.001

- Penny Sisto- Muhammed Ali POW! 1999.3.001

2000

- Wayne Ferguson- Kentucky Artist's Planters 2000.1.001

- Trent Ripley- Burbon Bottle 2000.2.001

2002

- Pamela G. Smith- Medium Handled Basket with Wide Band of Rings 2002.1.001

- Alma Lesch- Candy Canes 2002.2.001

- Alma Lesch- Judy O'Grady 2002.2.002

- Alma Lesch- Rebeccah 2002.2.003

- Alma Lesch- Small Untitled Wall Hanging 2002.2.004

- Alma Lesch- The Colonel's Lady 2002.2.005

- Alma Lesch- Thousand Pyramids Quilt 2002.2.006

- Alma Lesch- Stamp Quilt 2002.2.007

- Alma Lesch- Man Child 2002.2.008

- Alma Lesch- Mr. President 2002.2.009

- Chris Ramsey- Ambroisa Maple Bowl 2002.3.001

- Minnie and Garland Adkins- Fox Quilt 2002.4.001

- Gordon Andrus- Small Teapot with Rawhide Handle 2002.5.001

Figure 6 Permanent Collection Object List by Year Example 
Catalog Sheet

(Fine \& Decorative Arts, Historical objects)

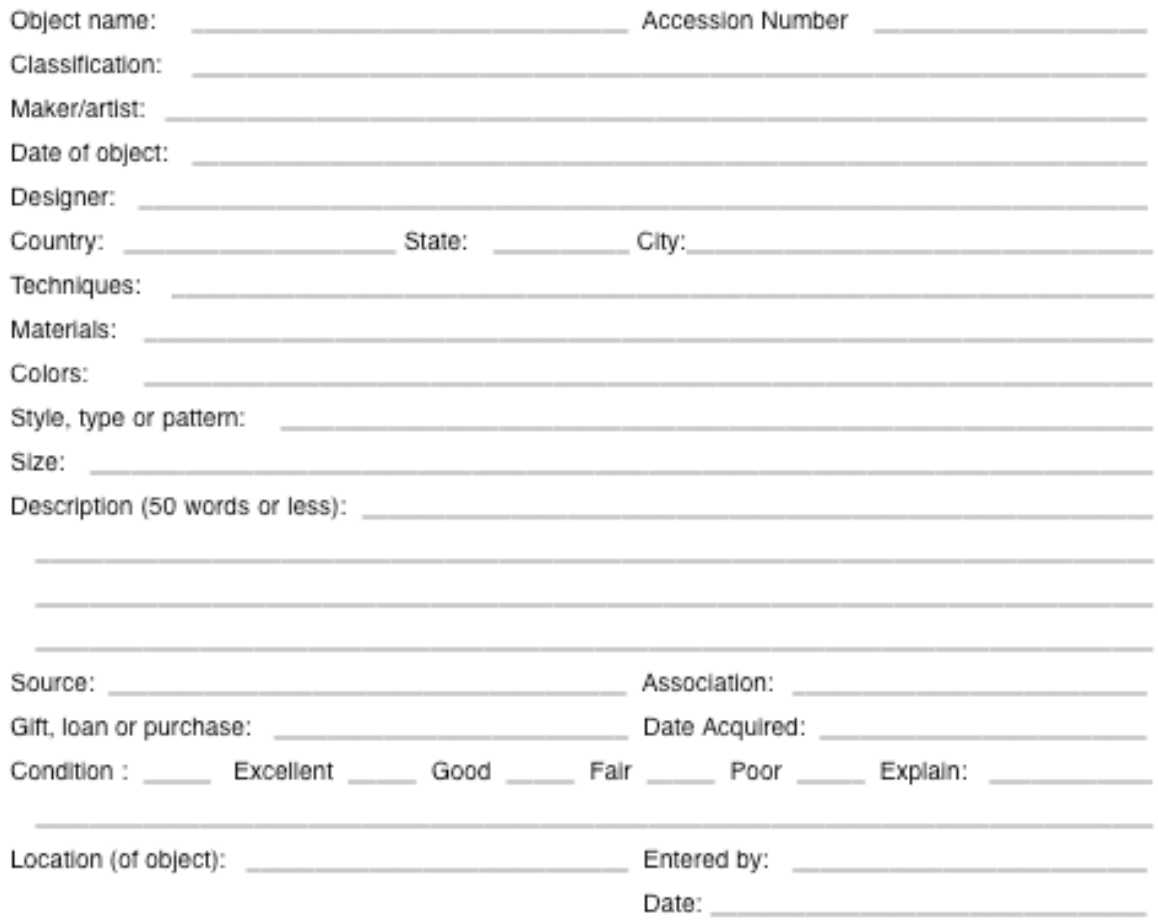

Figure 7 Illinois State Museum Catalogue Form 


\begin{tabular}{|l|l|}
\hline K E T UCKY M US E M M & $\begin{array}{l}\text { Kentucky Museum of Art and Craft } \\
\text { 715 West Main } \\
\text { Louisville, KY 40202 }\end{array}$ \\
\hline (502) 589-0102
\end{tabular}

Figure 8 Proposed Catalogue Form 
Classifications for Cataloguing:

- Wood

- Carving

- Lathe turned

- Stone

Fabricated

- Fiber

Lathe turned

- Quilt

- Sculpture

- Baskets

- Fabric Doll

- Ceramic

- Wheel thrown

- Carving

- Modeled

- Cast

- Raku

- Stoneware

- Painting

- Oil

- Acrylic

- Mixed Media

- Found Object

- Gourd

- Tree Roots

- Cow Skull

- Glass

- Hand Blown

- Cast

- Metal

- Fabricated

- Cast

- Photography

- Film

- Digital

- Mixed Media

- Collage

- Found object assemblage

- Paper

- Sculpture

Figure 9 Object Classifications List 


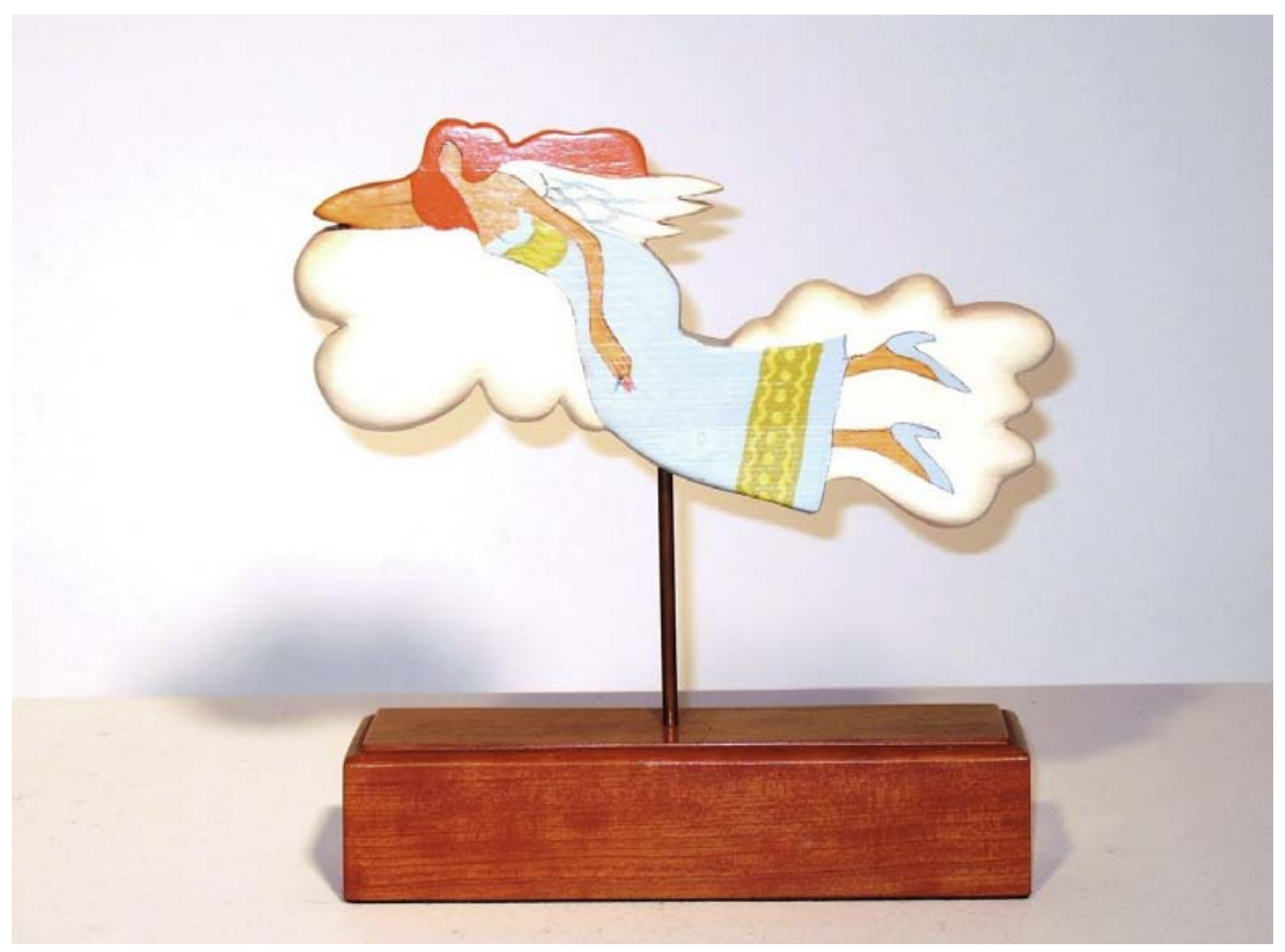

Figure 10 Angel by Charles Rolwing (Front). Wood and Acrylic. KMAC Permanent Collection.

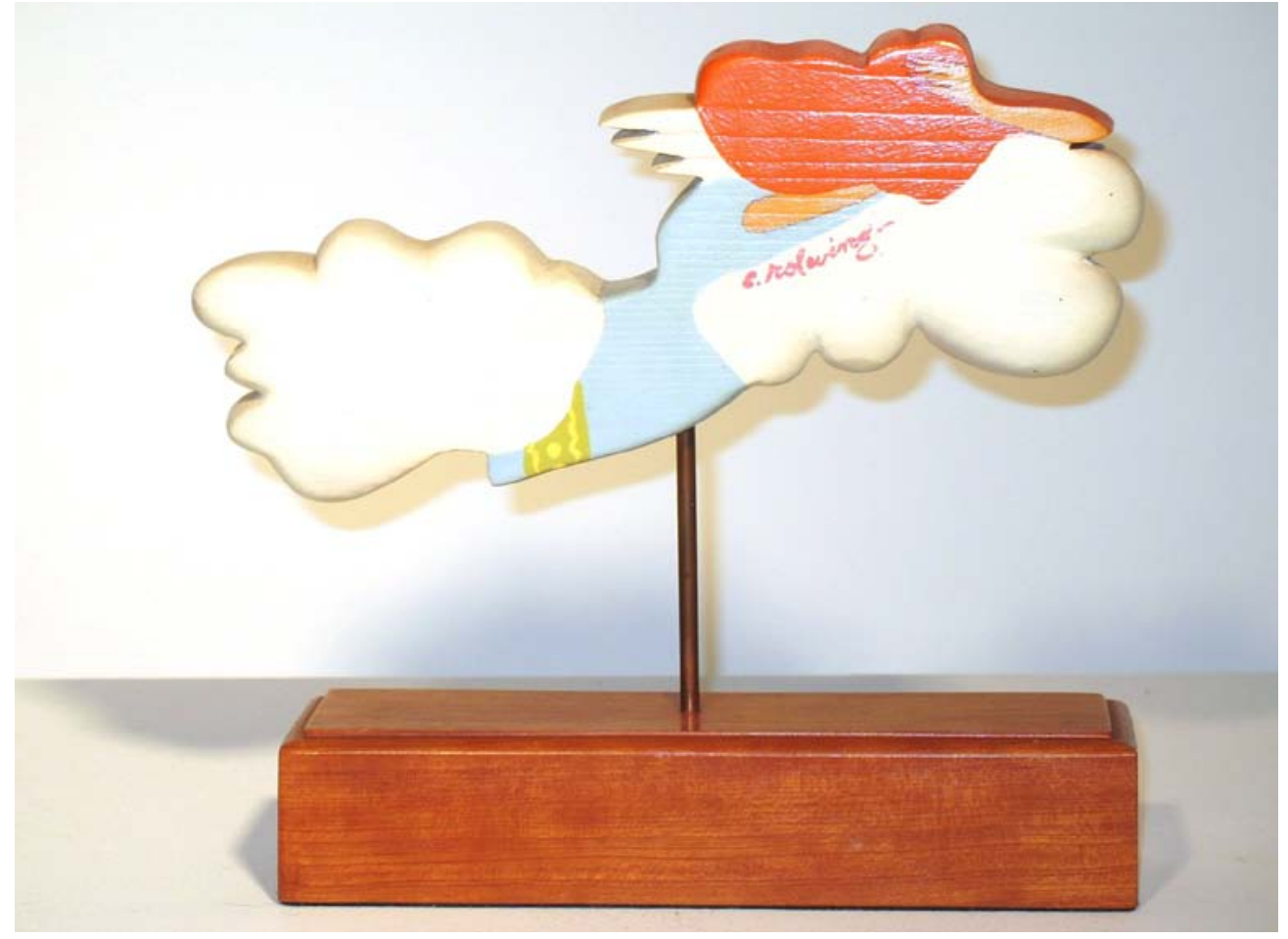

Figure 11 Angel by Charles Rolwing (Back). Wood and Acrylic. KMAC Permanent Collection. 


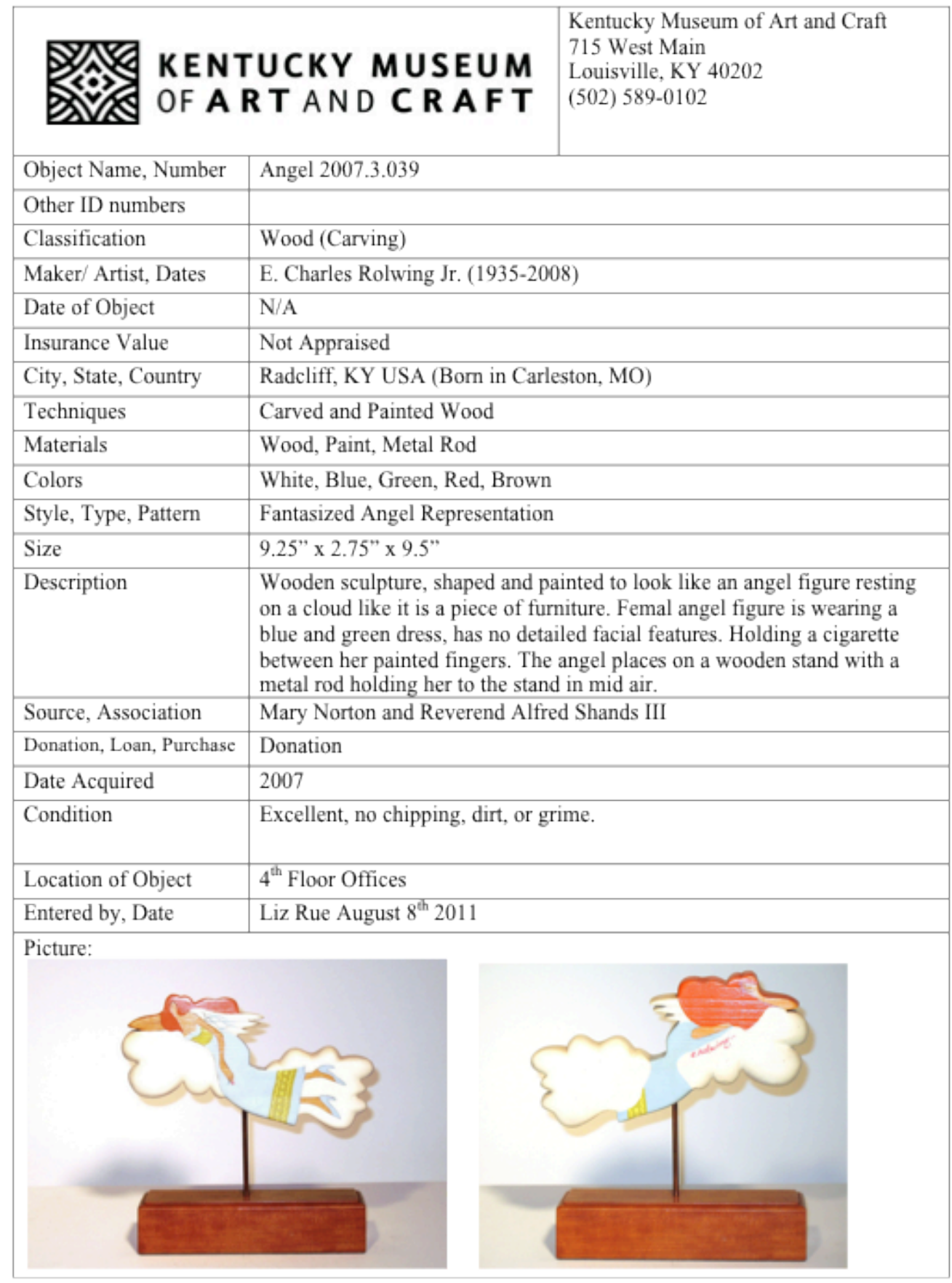

Figure 12 Catalogue Page for Charles Rolwing - Angel 


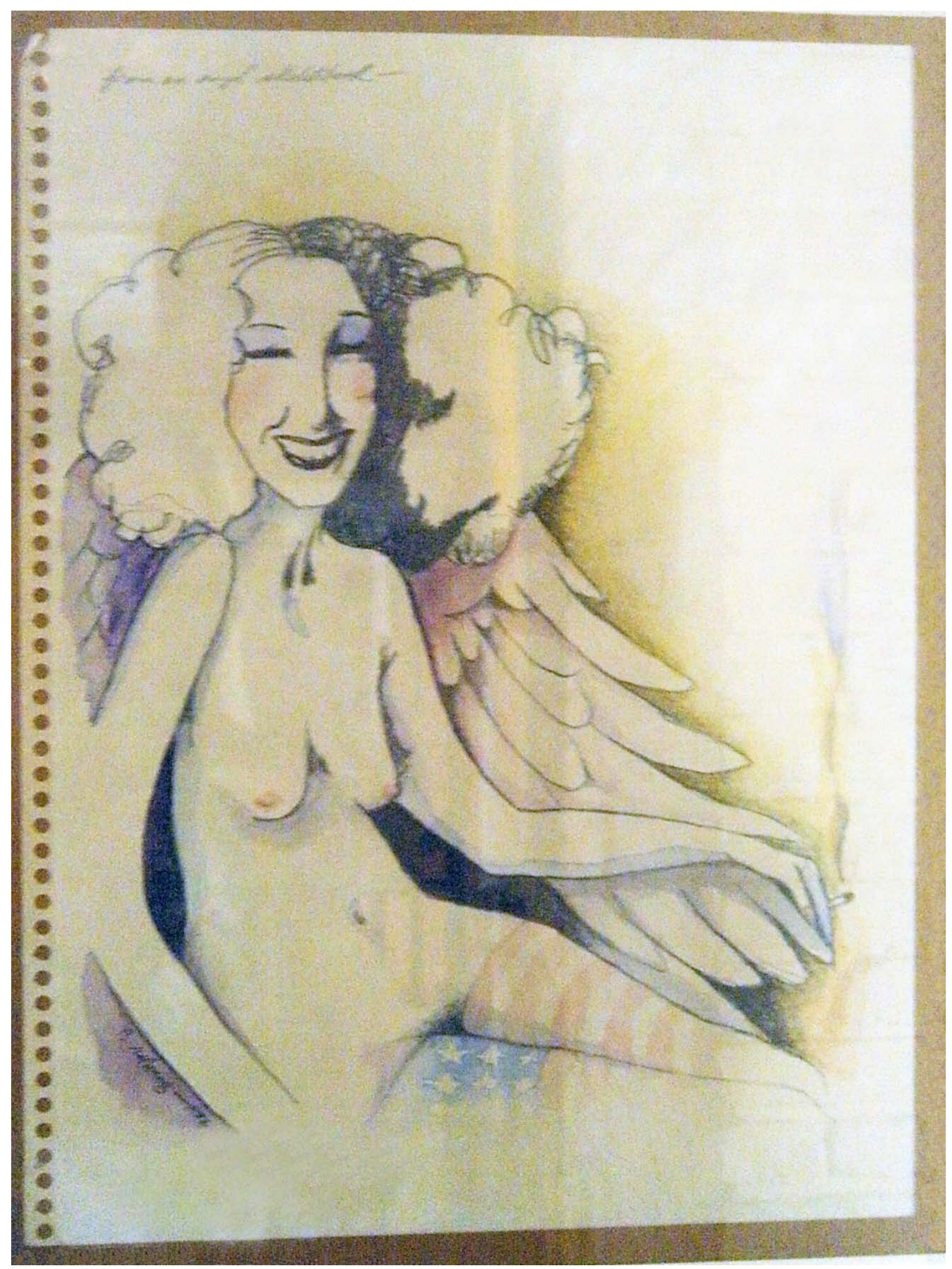

Figure 13 From an Angel Sketchbook, 1972 by Charles Rolwing. Pen and Ink on Paper. Collection of Dee Rolwing. 


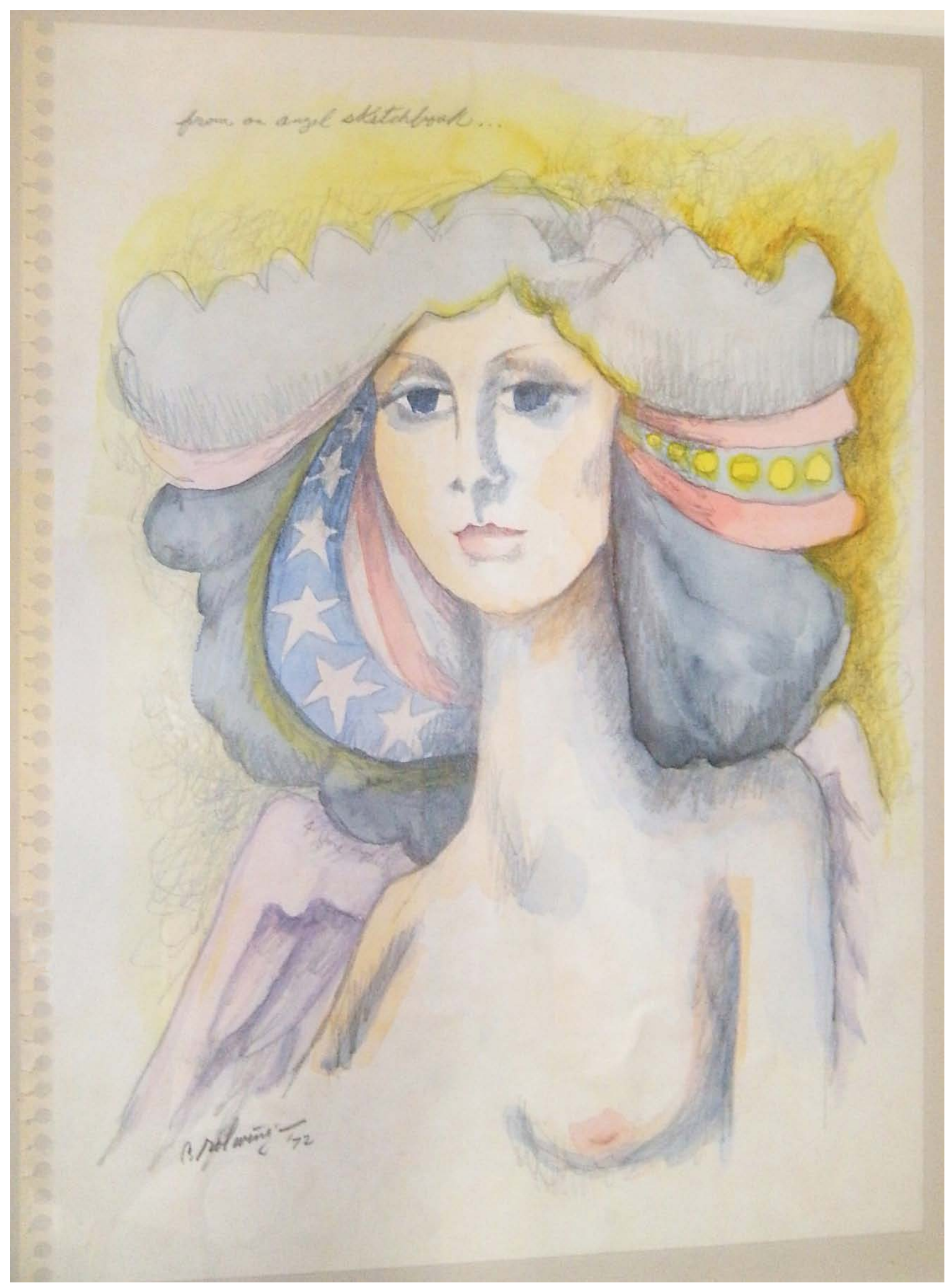

Figure 14 From an Angel Sketchbook, 1972 by Charles Rolwing. Pen and Ink on Paper. Collection of Dee Rolwing. 


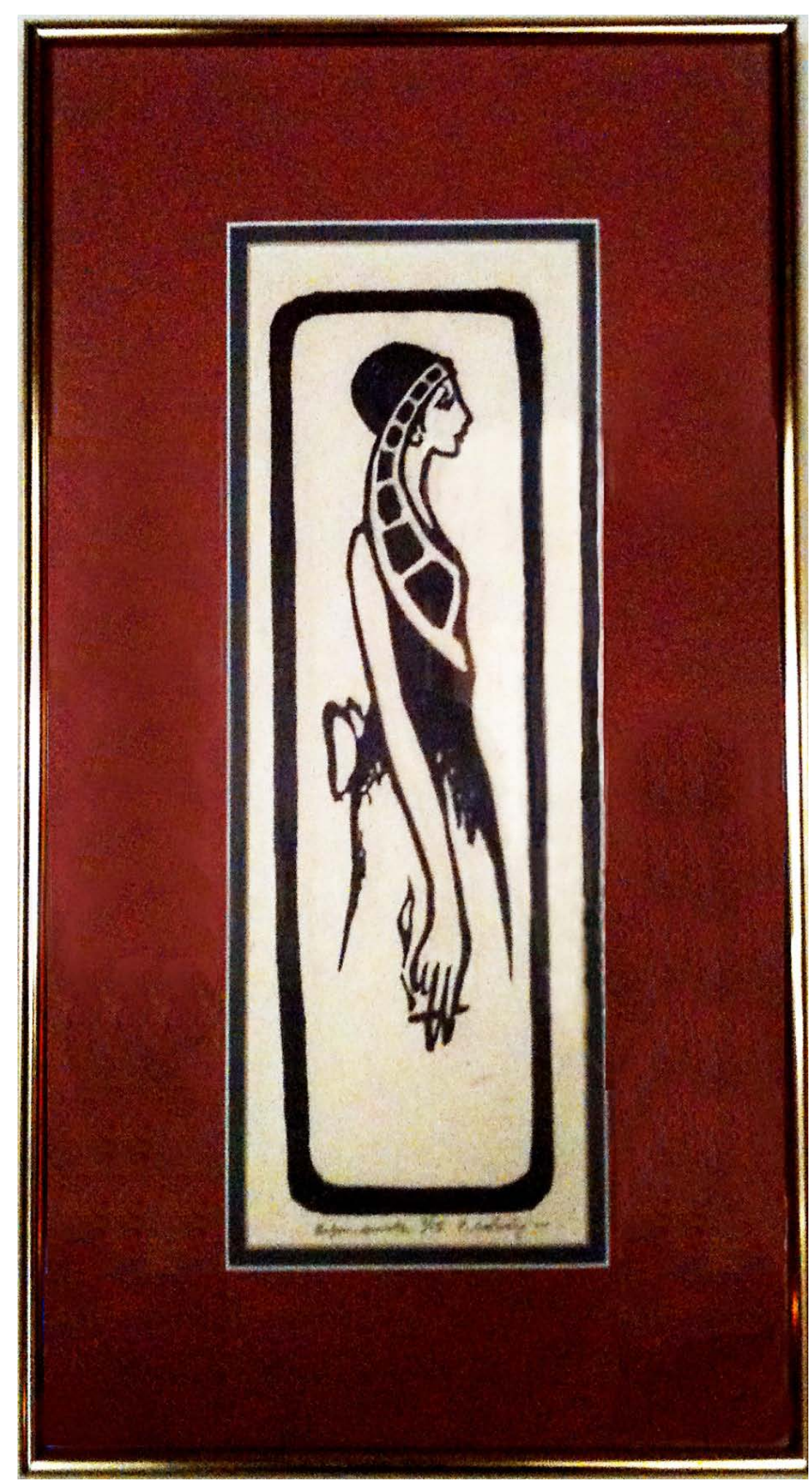

Figure 15 Cigar Smoker by Charles Rolwing. 3 of 13 Edition. Woodblock print on paper. Collection of Dee Rolwing. 


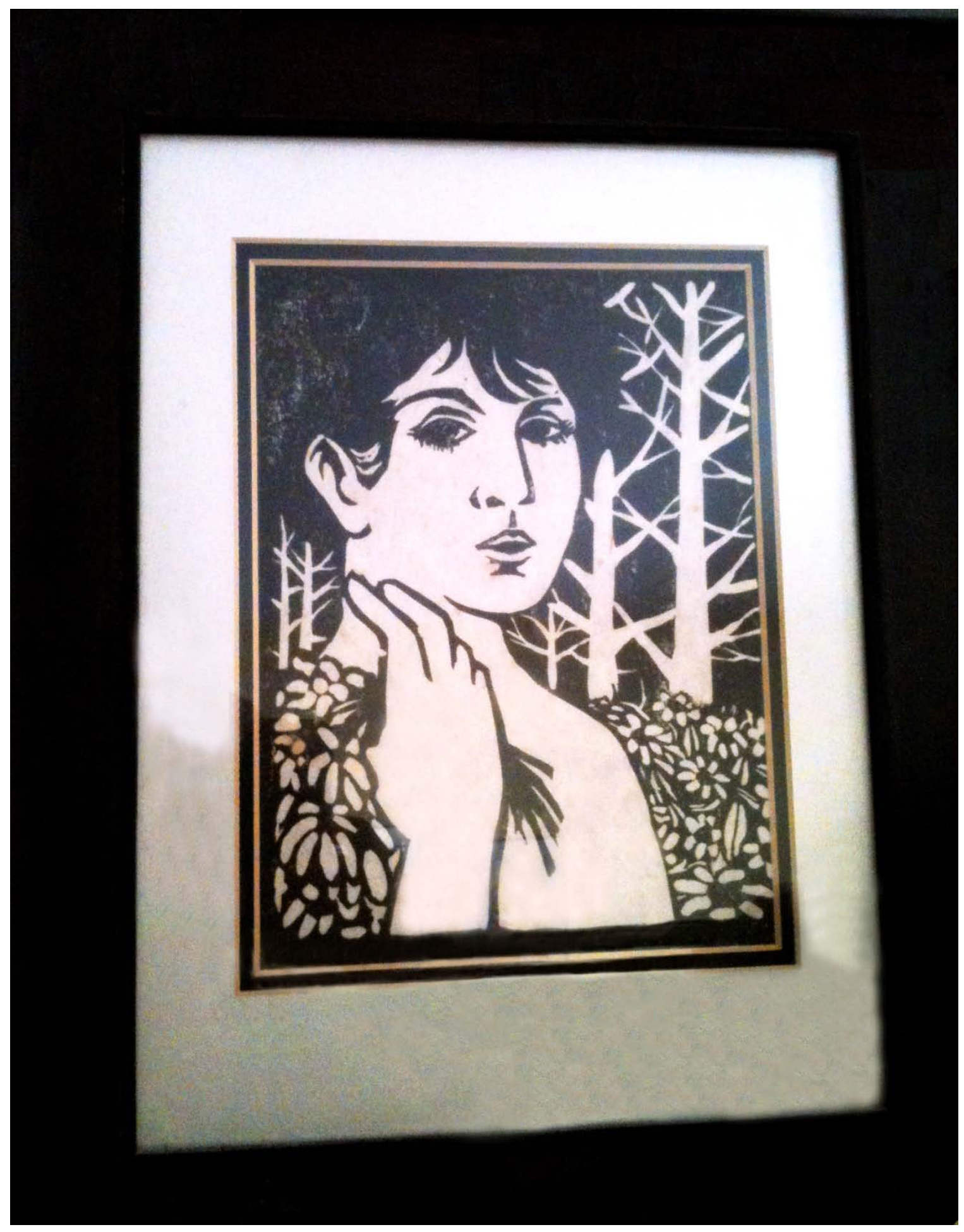

Figure 16 Untitled by Charles Rolwing. Woodblock Print on Paper. Collection of Dee Rolwing. 


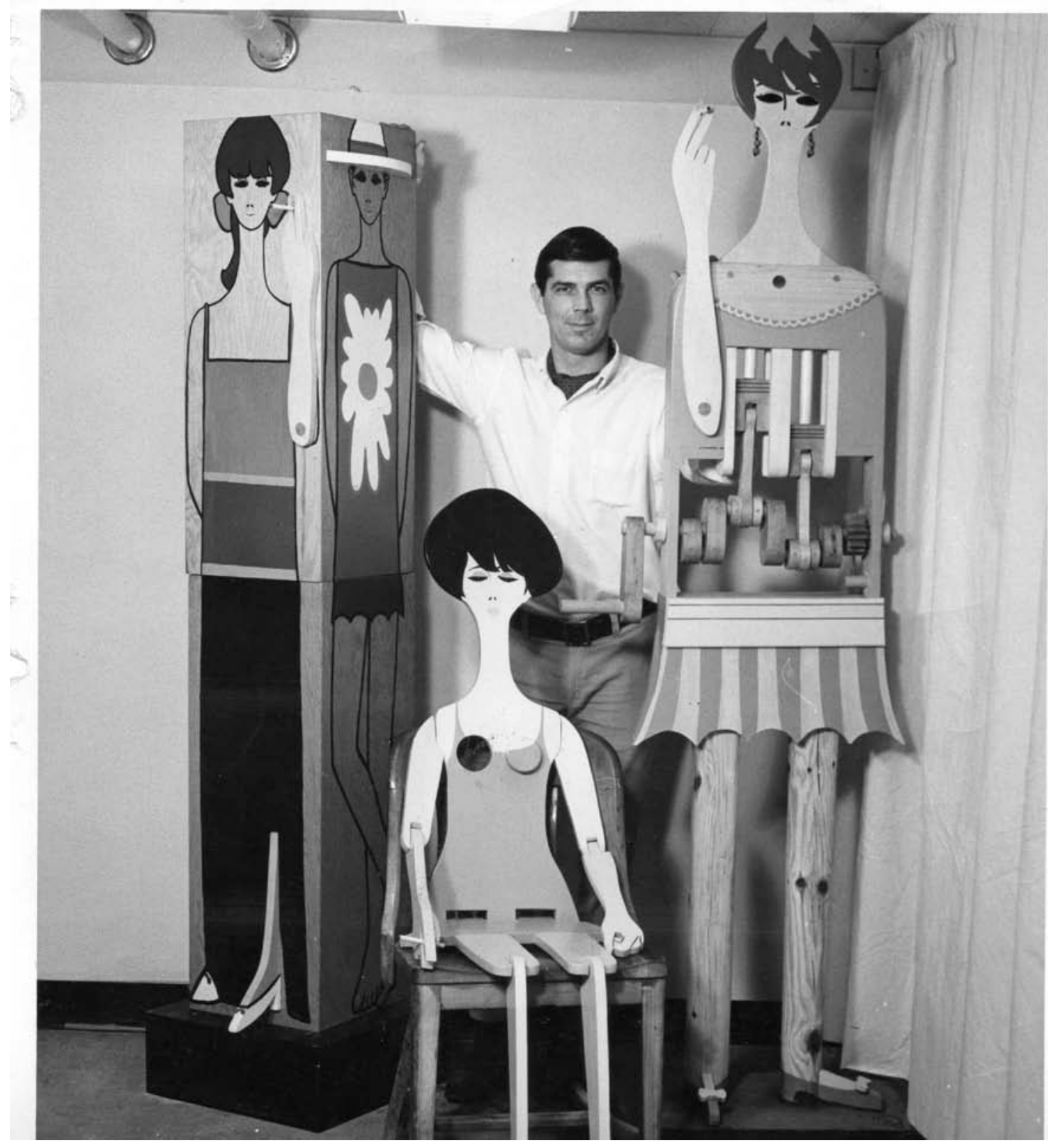

Figure 17 Charles Rolwing with Large Wooden Female Sculptures 


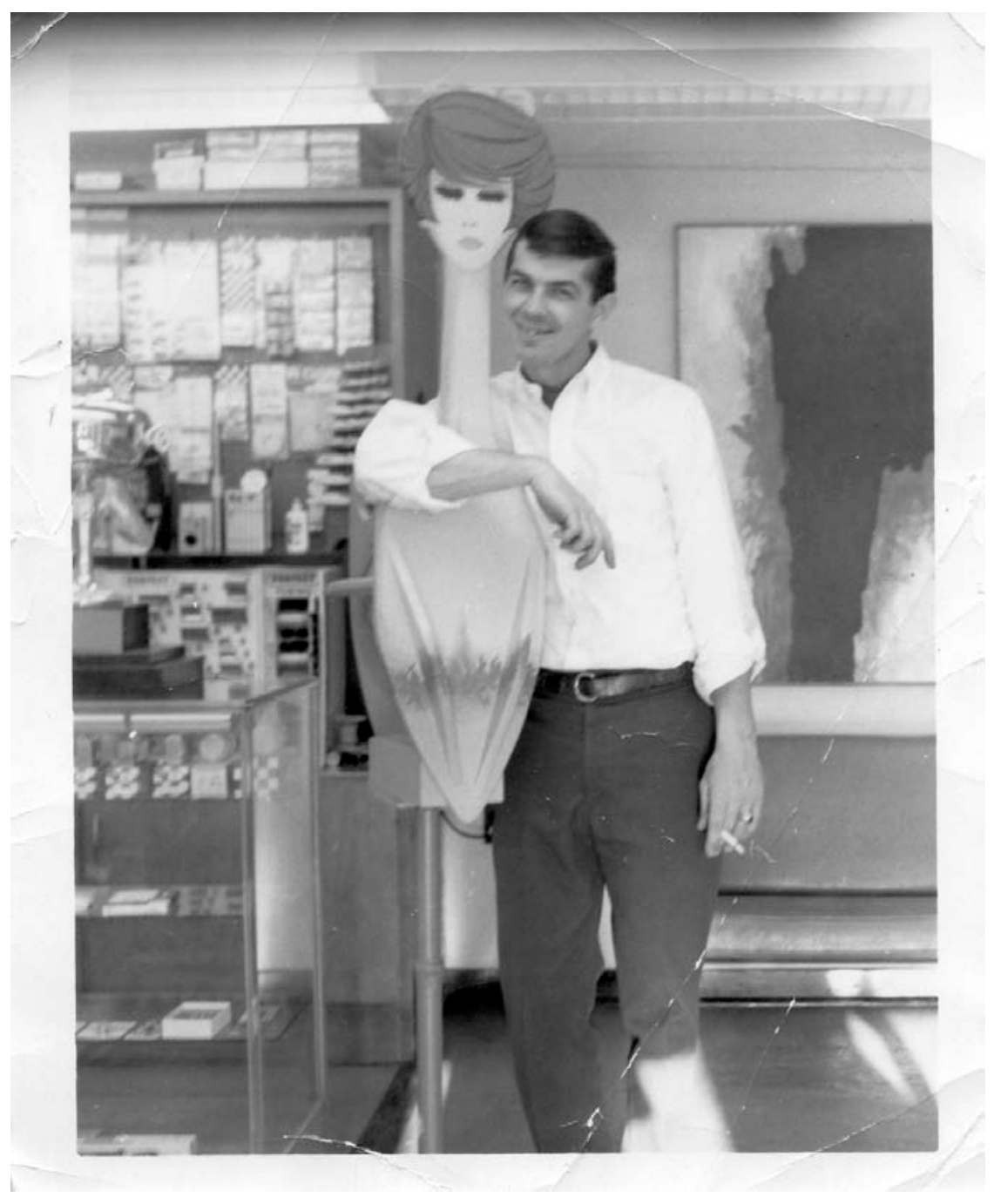

Figure 18 Charles Rolwing and Large Wooden Female Figure 

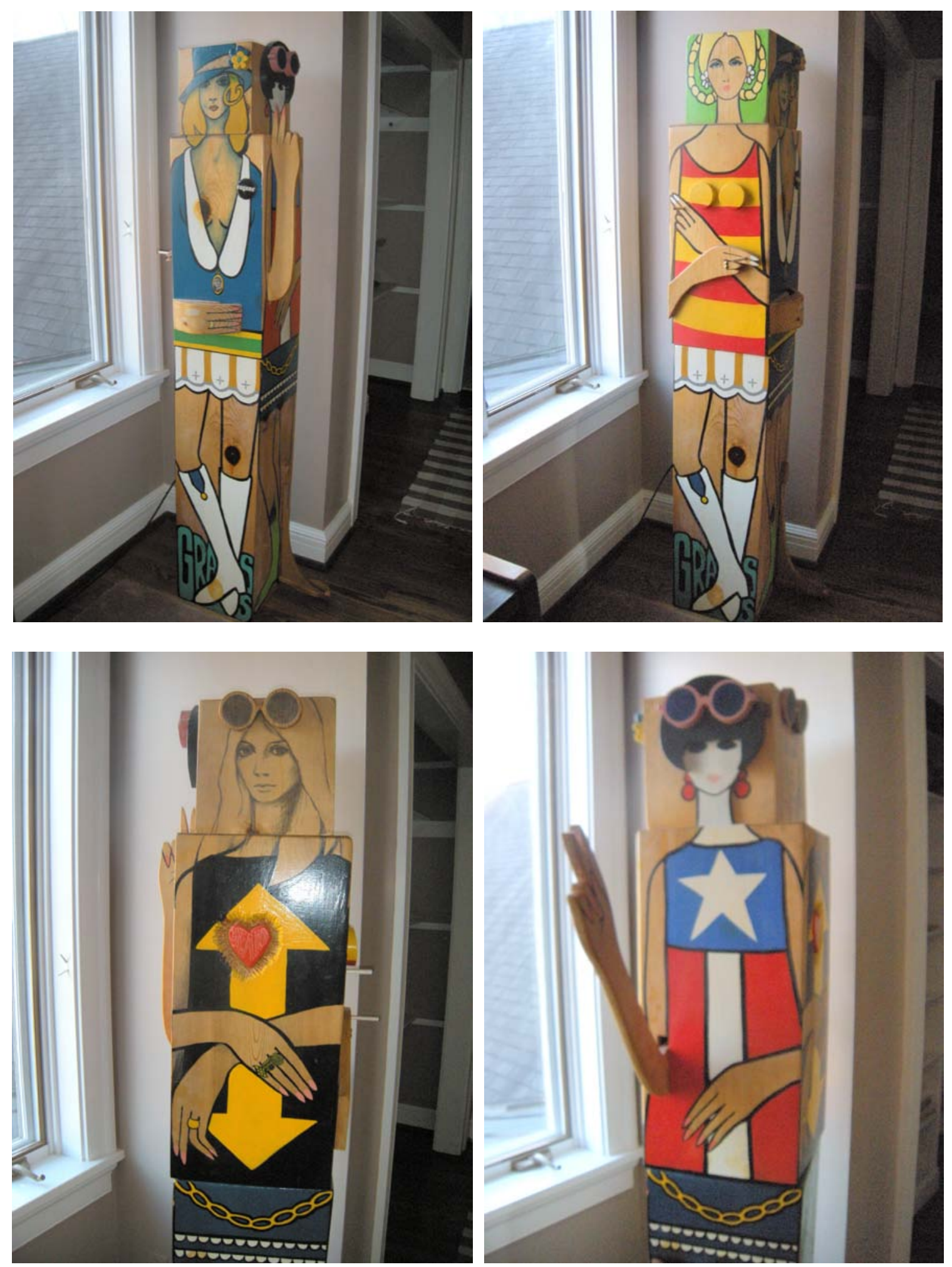

Figure 19 Untitled Four Women by Charles Rolwing. Wood, Acrylic, Pencil. Collection of Marlene Grissom. 


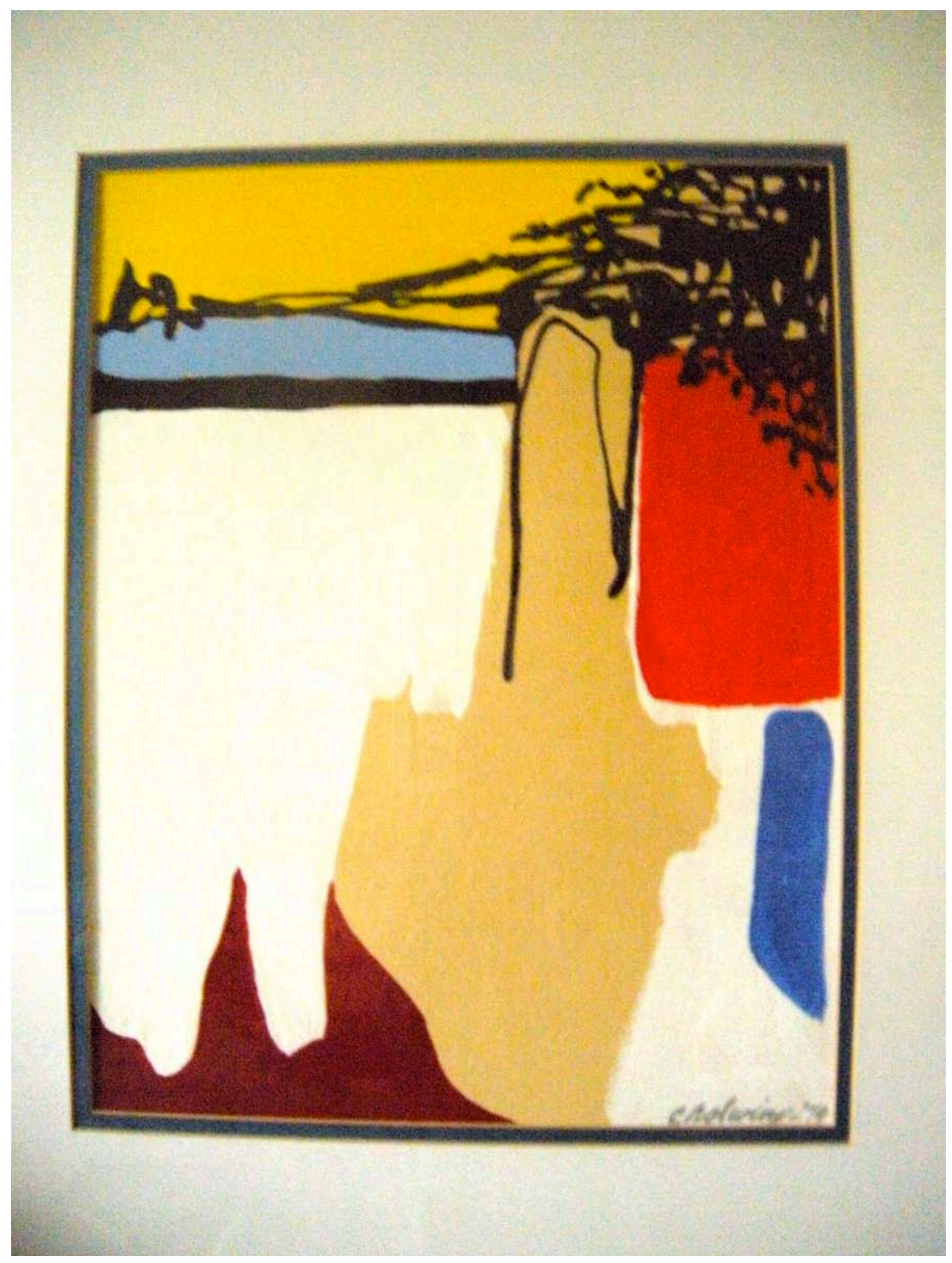

Figure 20 Untitled, 1974 by Charles Rolwing. Acrylic on Paper. Collection of Dee Rolwing. 


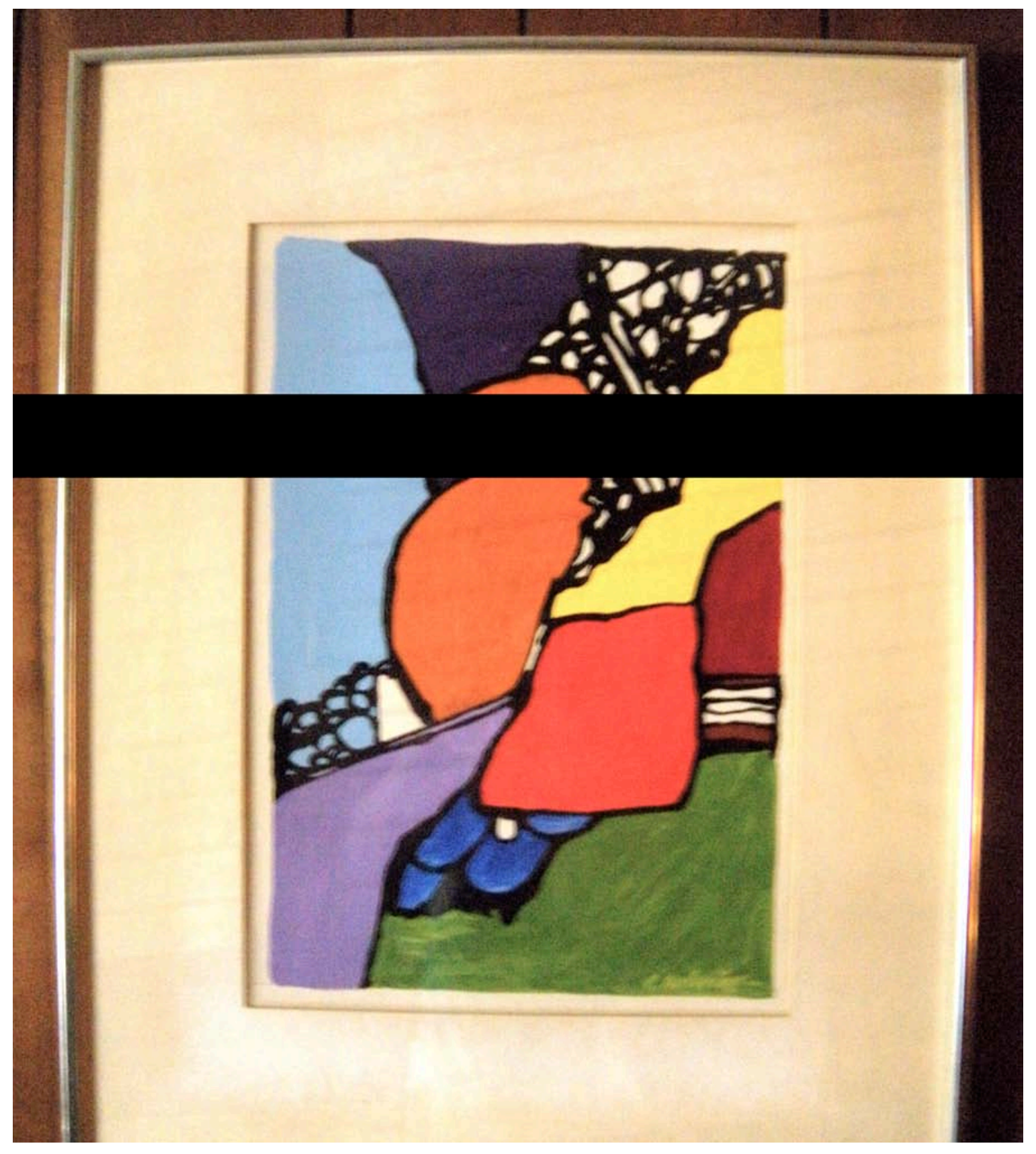

Figure 21 Untitled by Charles Rolwing. Acrylic on Paper. Collection of Dee Rolwing. 


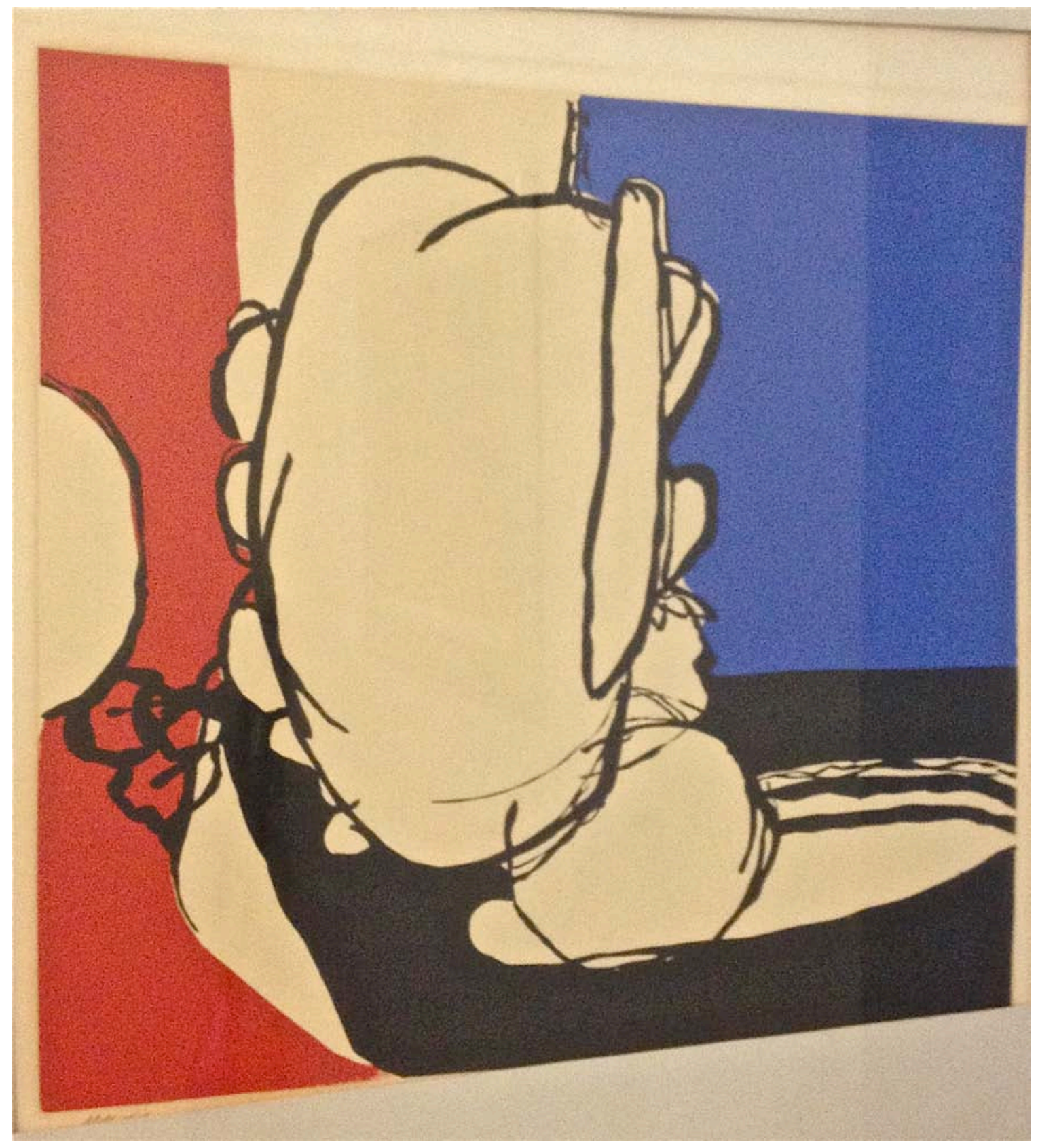

Figure 22 Still Life by Charles Rolwing. Acrylic on Paper. Collection of Carol Swearingen. 


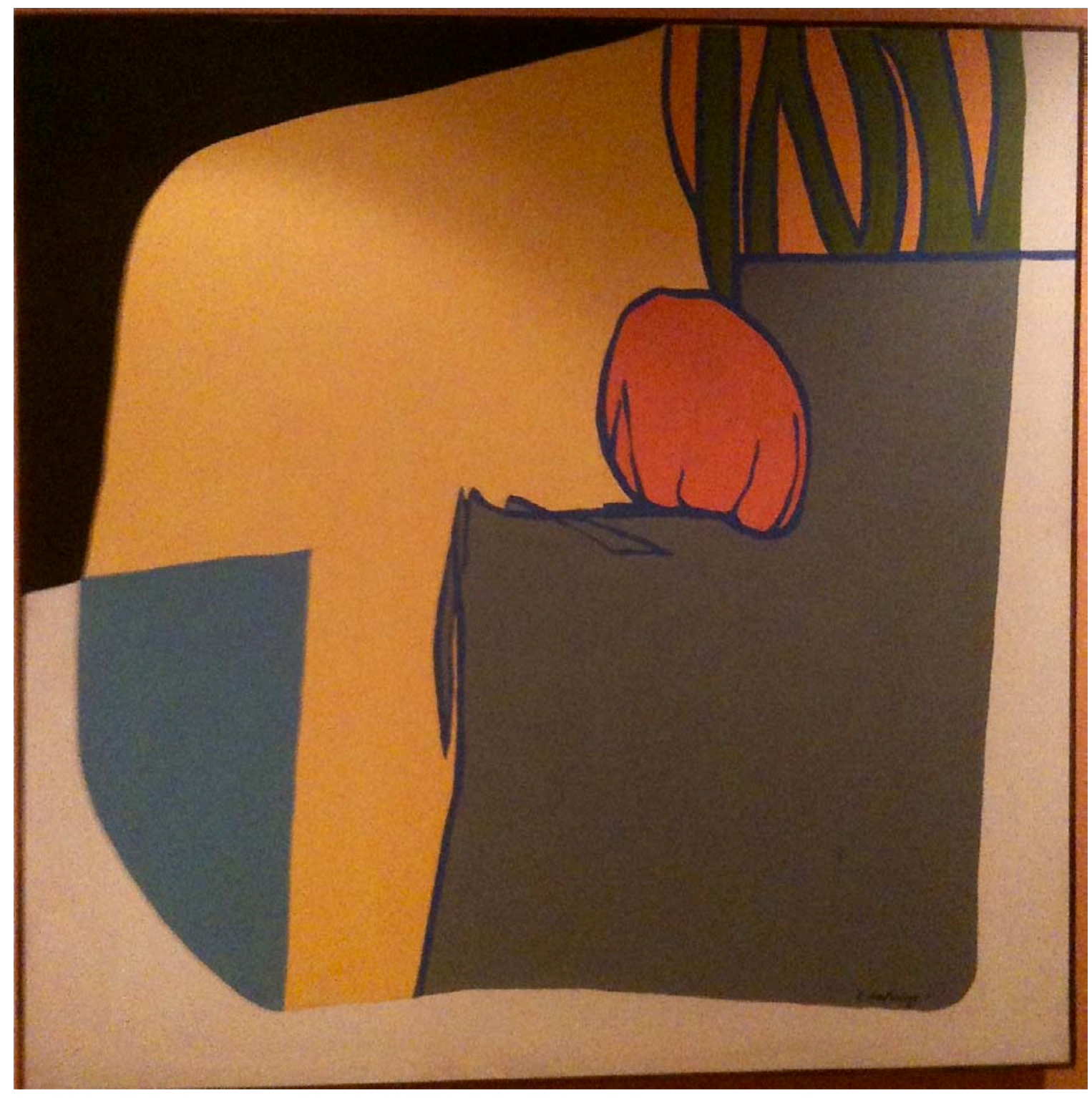

Figure 23 Untitled by Charles Rolwing. Acrylic on Canvas. Collection of K Shaver. 


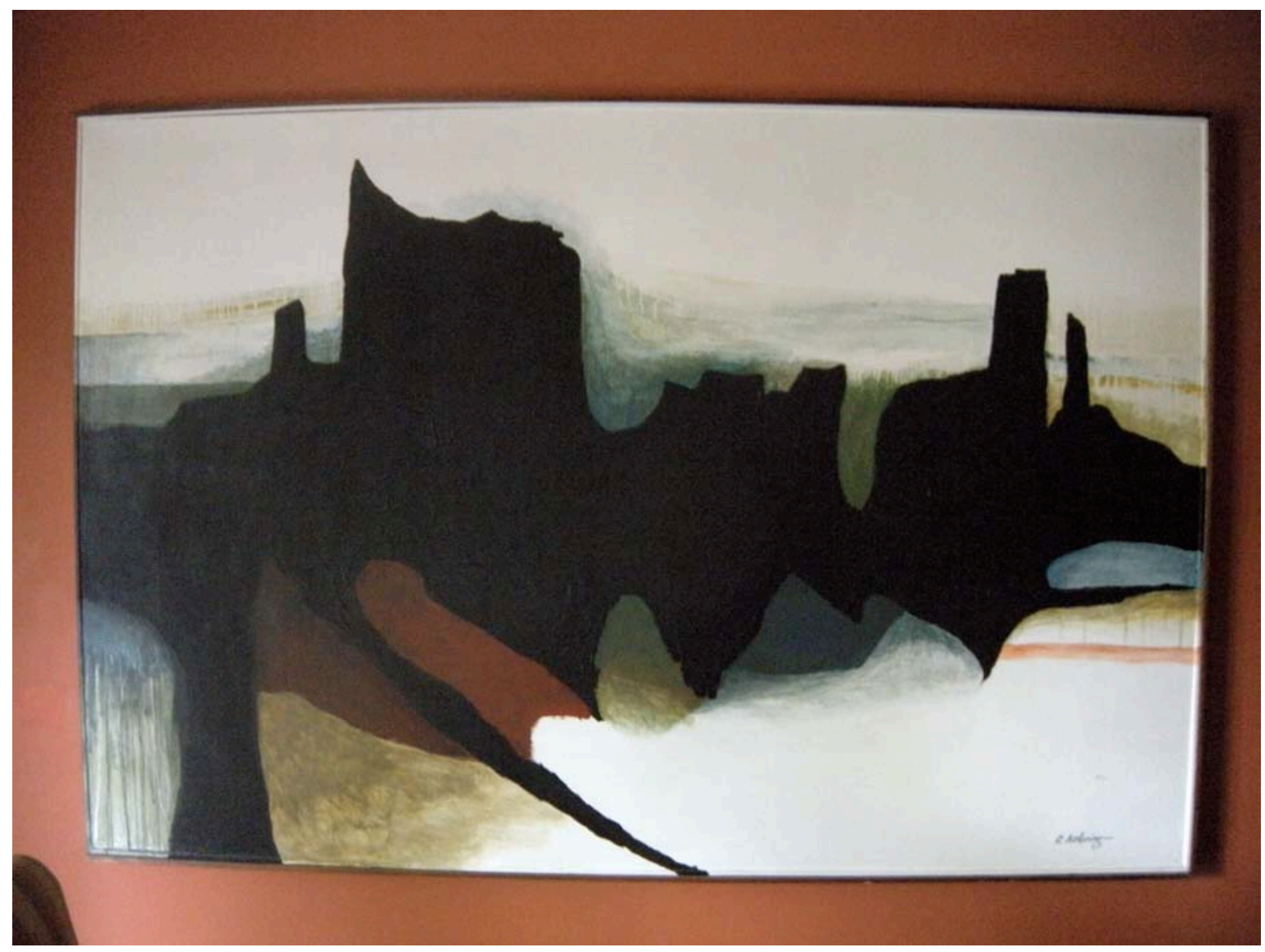

Figure 24 Untitled Western Landscape by Charles Rolwing. Oil on Canvas. Collection of Dee Rolwing. 


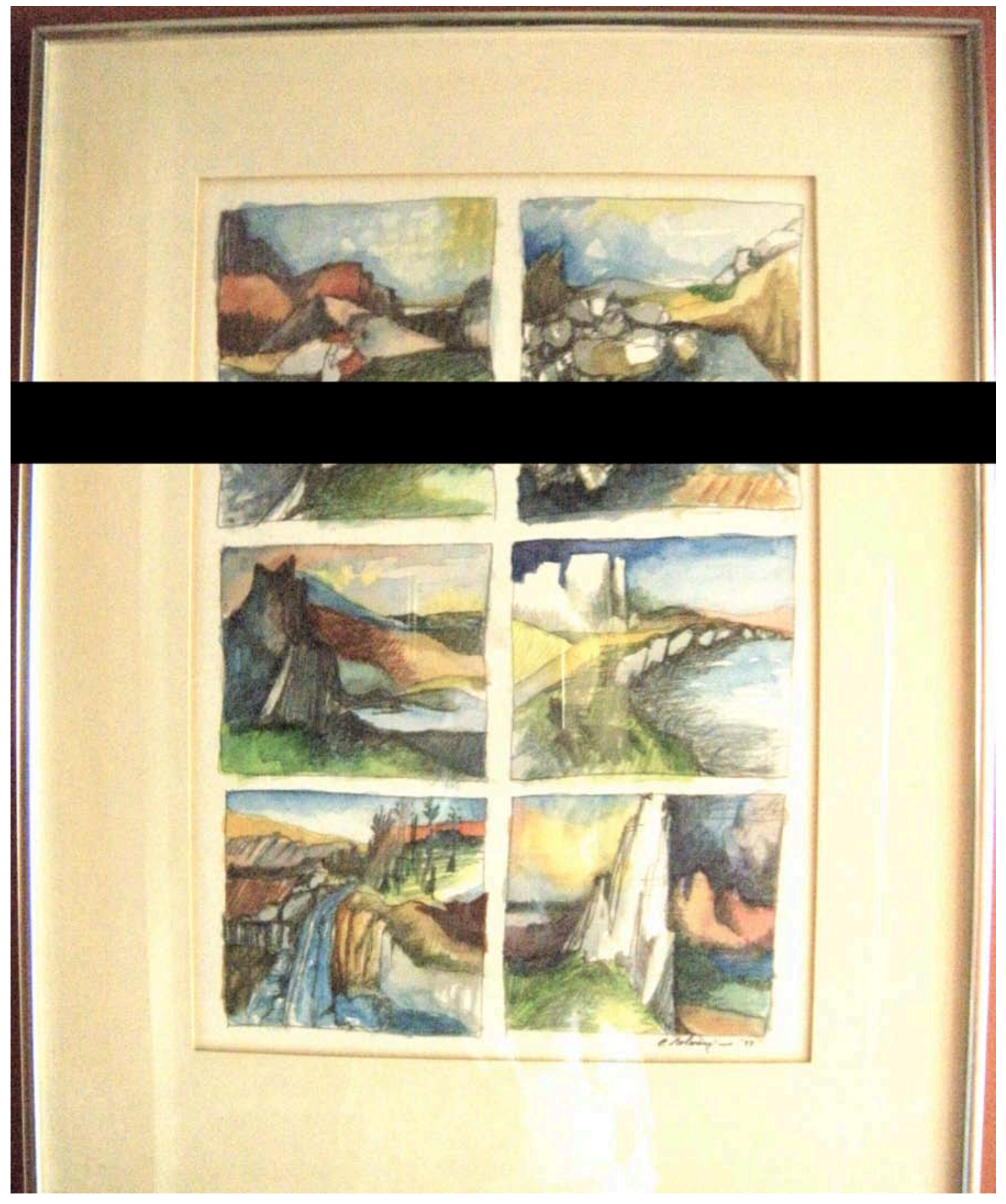

Figure 25 Untitled Western Six Pack, 1977 by Charles Rolwing. Watercolor and Pencil on Paper. Collection of Dee Rolwing. 


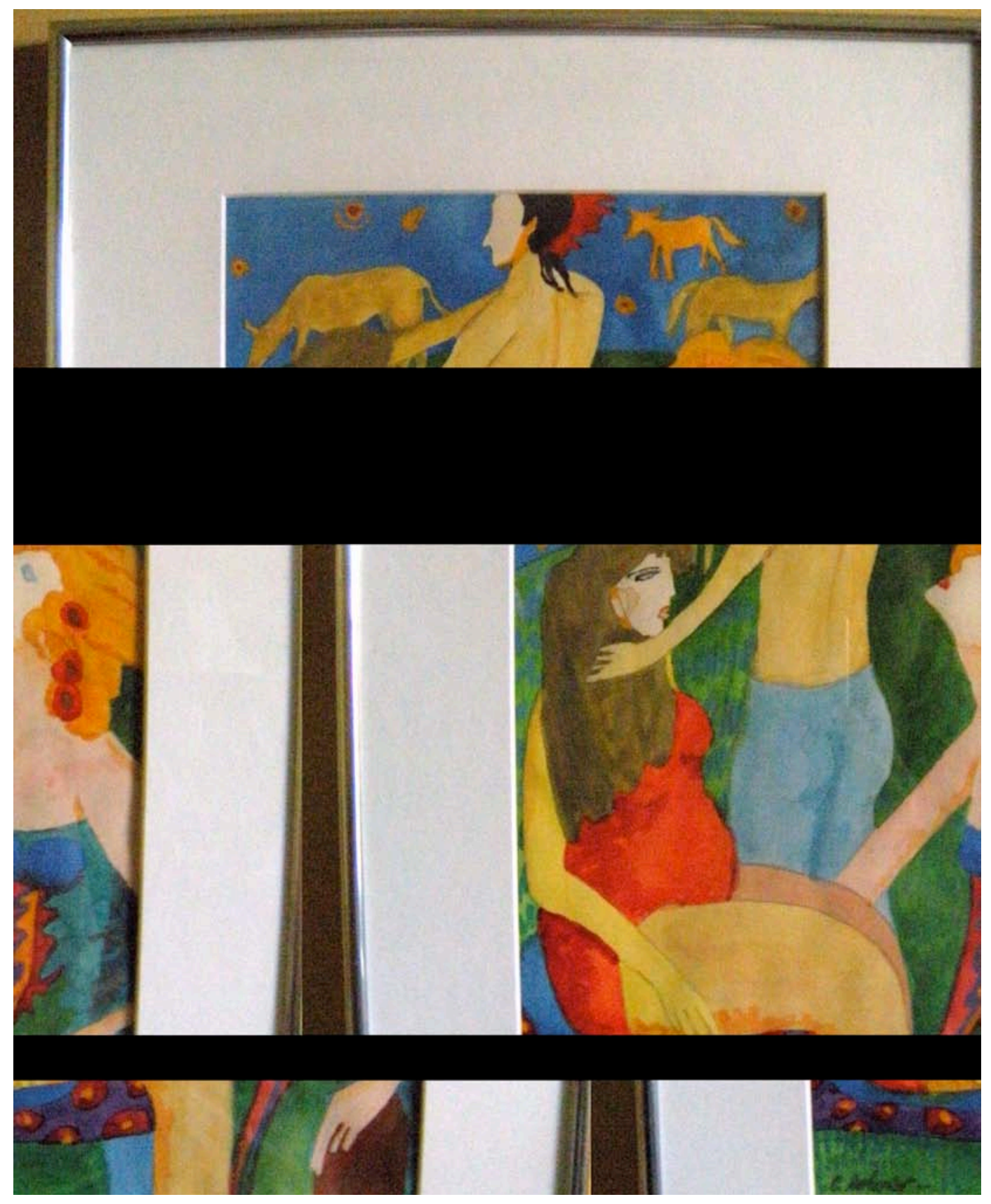

Figure 26 Untitled by Charles Rolwing. Watercolor on Paper. Collection of Dee Rolwing. 


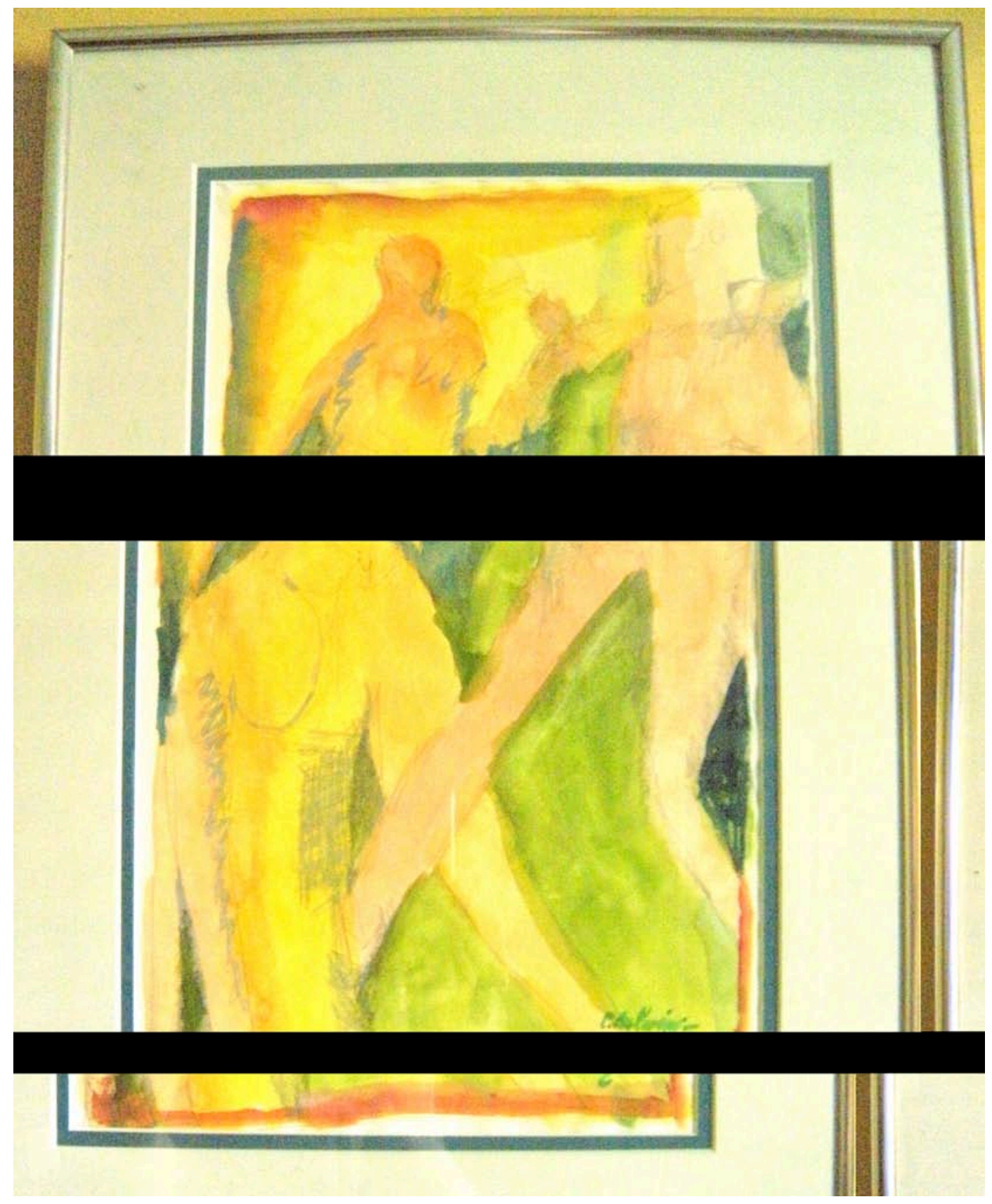

Figure 27 Untitled by Charles Rolwing. Watercolor on Paper. Collection of Dee Rolwing. 


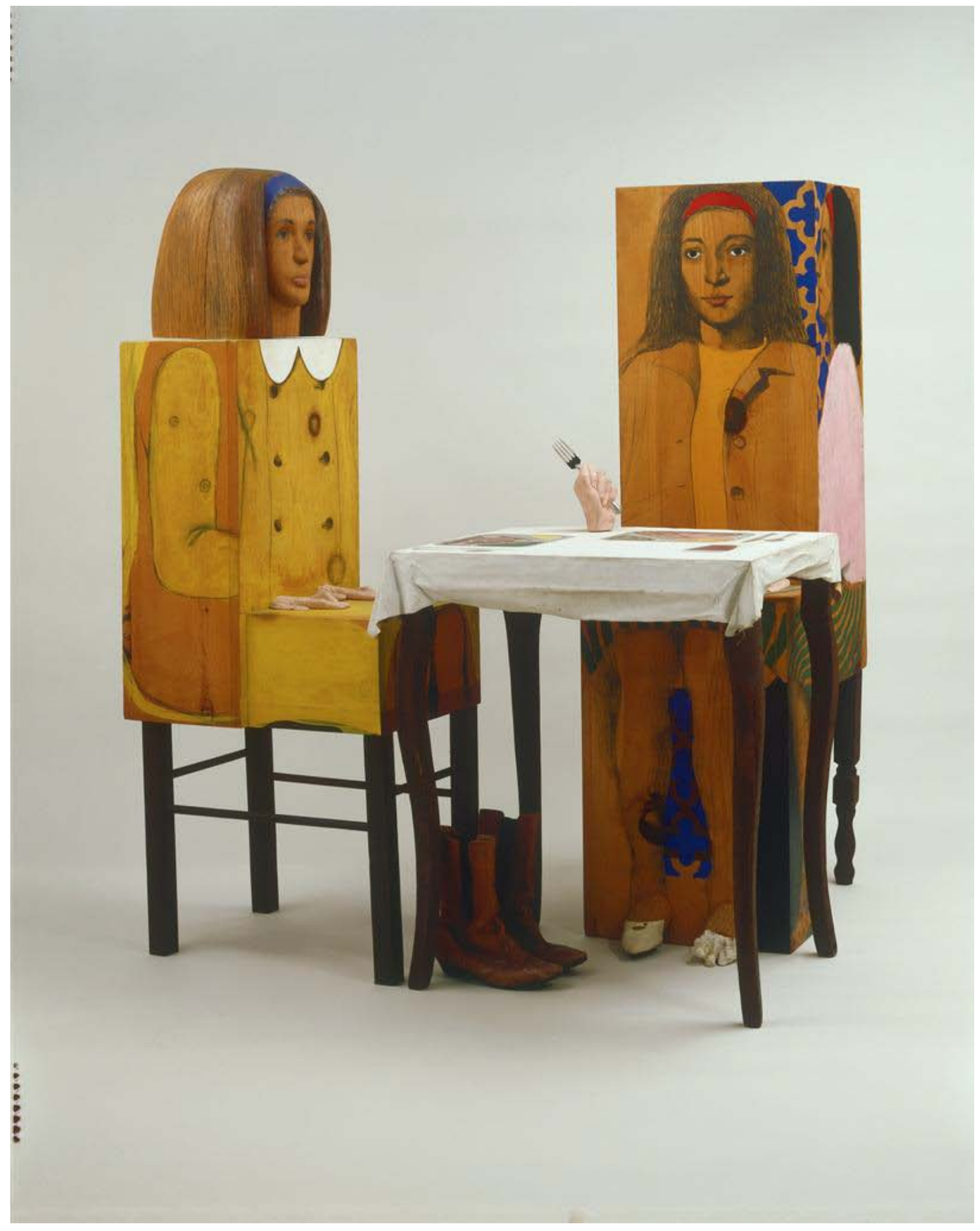

Figure 28 Dinner Date, 1963 by Marisol Escobar. Painted wood, plaster, textiles, Oil on Canvas, metal fork, leather boots, paint, graphite. Collection of Yale University Art Gallery. 


\section{CURRICULUM VITAE}

NAME

Elizabeth Anita Hampton Rue

ADDRESS

1745 Deer Lane Apt 4

Louisville, KY 40205

DATE OF BIRTH

Louisville, Kentucky - September 7, 1988

EDUCATION

Bachelor of Arts in Art History $\quad$ June 2010

Ohio University

Cum GPA: 3.326; Major GPA 3.66

Studied Abroad A Summer Quarter in Italy; studying Roman Art, Medieval Art, Quattrocentro Art, and Cinquecentro Art

Fine Art Training One Year of Foundation Studies studying Drawing, Painting, and Three-Dimensional Studies

Master of Arts in Critical and Curatorial Studies

May 2012

University of Louisville

Cum GPA 3.52

\section{$\underline{\text { EXHIBITIONS }}$}

Convergence III

June 2011

Assistant Curator at Kentucky Museum of Art and Craft Louisville, KY

Face Time: Examining Authority

June to August 2011

Class Project: Helped Assemble and Develop Exhibit Cressman Center

Louisville, KY

$\underline{\text { PUBLICATIONS }}$

Masters Thesis

April 2012

Unearthing Charles Rolwing: The Problem of Documentation in the Small

Museum 


\section{EXPERIENCE}

\section{Curatorial Intern}

February 2011 - Current

Kentucky Museum of Art and Craft Louisville, KY

- Created an accession number system and a catalogue for a 300+ piece permanent collection

- Helped prepare incoming objects for temporary exhibitions

- Created object labels for the permanent collection and for temporary shows

Archival Intern June 2011 - February 2012

Louisville Rotary International Club Louisville, KY

- Created an alphabetical organization system for the filing of documents

- Researched through newsletters, director's notes, and other documents dating from 1912 to present in preparation for the club's centennial celebration

\section{Curatorial Intern}

March - June 2010

Kennedy Museum of Art Athens, $\mathrm{OH}$

- Created an educational exhibition proposal on Burhan Dogancay, an artist located in the permanent collection

- Research on Clarence White, a photographer in the permanent collection

Artist Assistant

June - July 2008

Ann Stewart Anderson Louisville, KY

- Researched the Nine Museses in preparation for her comission

- Prepared the frames for the paintings in the Nine Museses commissioned by the University of Louisville for the Bingham Poetry Room of Ekstrom Library

\section{$\underline{\text { SKILLS }}$}

\section{Language}

\section{Technology}

Intermediate Proficiency in German, English (Native), Beginner in Italian

Proficient in Macintosh and PC systems, File Maker Pro, Photoshop, Word, Excel, Publisher, PowerPoint, Quark Express, Wordworks 